Journal of

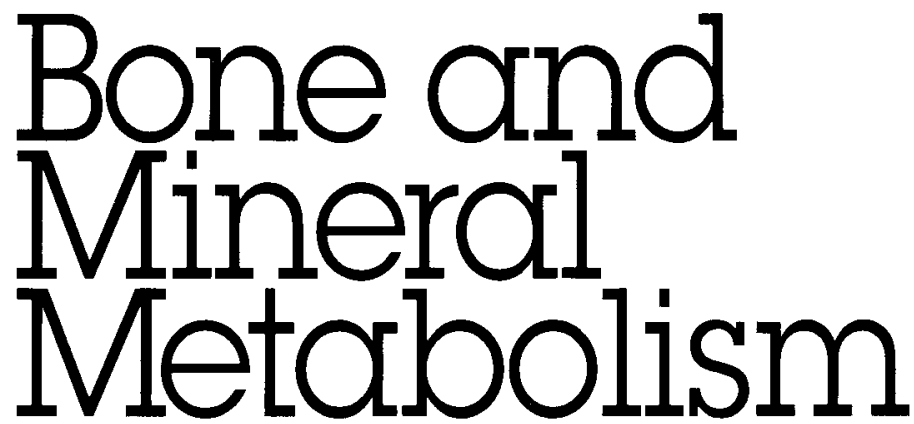

\title{
International Symposium on Cartilage Metabolism
}

Senri Life Science Center, Toyonaka, Osaka, Japan November 16-18, 1994

Chair/Fujio Suzuki, Co-Chair/Barbara D. Boyan

Sponsored by Osaka University

\section{Abstracts}

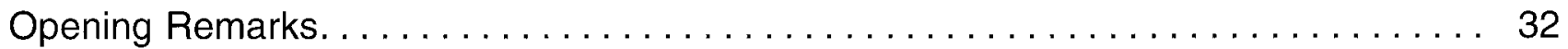

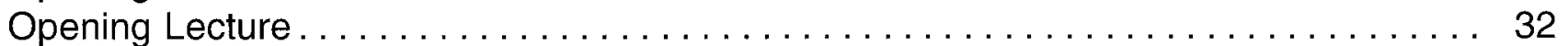

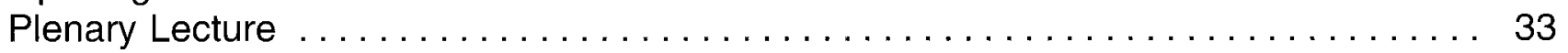

Structure and Function of Cartilage ECM $\ldots \ldots \ldots \ldots \ldots \ldots \ldots \ldots \ldots \ldots \ldots \ldots \ldots \ldots \ldots \ldots$

Normal and Pathologic Metabolism of Cartilage ..................... 36

Endochondral Bone Formation and Mineralization .................. 44

Regulatory Mechanism of Expression of Cartilage-Phenotype .............. 46 
32

\section{Opening Remarks}

Distinguished guests, ladies and gentlemen, Good morning. It is a privilage to welcome you to Osaka for the International Symposium on Cartilage Metabolism 1994. In the last decade or so, there has been a tremendous expansion of knowledge in the various aspects of cartilage reseach. For example, our knowledge of chondrocyte differentiation, synthesis of extracellular matrices, the structure and function of the epiphyseal growth plate and of articular cartilage has enormously increased. Research in molecular biology on cartilage growth and differentiation has also extensively advanced. These advances will lead to advances in the treatment and prevention of disease processes in which cartilage may be involved. The purpose of this symposium is to bring together cell and molecular biologists, structural chemists, morphologists, and clinical investigators who are concerned about the cartilage metabolism. This symposium will be held in the following topics, 1) Structure and function of cartilage extracellular matrix, 2) Normal and pathologic metabolism of cartilage, 3) Endochondral bone formation and mineralization, 4) Regulatory mechanism of expression of cartilage-phenotype. Therefore, Dr. Barbara Boyan and I hope that our honorable guests coming from abroad and from Japan will update themselves on recent advances in the area of cartilage research.

Furthermore, since this ISCM is the first of its kind, I would like to propose that ISCM will be held consecutively every other year (or every year) and perhaps the next ISCM will be held openly to the public, not semi-closed as this time, somewhere in 1996 or so. I very much hope that this ISCM'94 marks only the beginning of a long and flourishing existence.

This symposium is dedicated to the late Professor Emeritus Shiro Akabori, a great Japanese scientist and the 7th President of Osaka University, for his valuable contributions to life science.

Finally, Dr. Barbara Boyan and I express our gratitude towards Osaka University for the financial help. We also acknowledge with gratitude the invaluable help of the Center for Academic Societies, Osaka and many Japanese pharmaceutical industries. I hope that all of you will enjoy this symposium and happy stay here. Thank you..

\section{Opening Lecture}

A HISTORICAL REVIEW OF CARTILAGE RESEARCH IN IAPAN

\section{Fujio Suzuki}

Deparment of Biochemistry, Faculty of Dentistry, Osaka University, Suita, Osaka 565, Japan

The Japanese took over Chinese medicine together with Chinese culture in the 9 th century. Tanba, Yasuyori published the first publication in medicine in 982 . In the 18th volume of this series, he described bone and articular diseases. Under Dutch influence the Japanese made great progress in surgery in the 17th century. Hanaoka, Seishu (1760-1835) succeeded in preparing an anesthetic substance from herbs. It was made up six mixtures of the extracts of roots, seeds and stalks of plants. He tried it on a woman suffering from breast cancer and removed it by the aid of Dutch style surgical instruments in 1805 . His method was tried 37 years before the first use of ether as general anesthesia by Long, C. W. in 1842. We can see in Hanaoka's achievements, fusion of oriental and occidental medicine and also originality and his pioneering spirit.

Ogata, Koan (1810-63) studied Dutch medicine in Osaka, Edo and Nagasaki. After returning home, he opened a private acedemy "Tekijuku" in Osaka in 1838. Young students inspired by Ogata's high personality and career, gathered to his academy from many areas of the country. From 1838 to 1862 , more than a thousand students entered Tekijuku and many graduates made great contribution not only in the field of medicine but also in several other areas in the periods before and after Meiji Restoration. Tekijuku is the forerunner of Osaka University Medical School.

Soon after the Meiji Restoration in 1868, some governmental colleges were established for conducting higher education of western science and technology. As the teaching staff of these colleges a number of scientists were invited from Western countries. In the final stage of the Edo Era, around the middle of the $1860 \mathrm{~s}$, the influential power of foreign countries over Japan shifted from the Netherlands to England and France. When the influence of Germany became prominent, many of the leaders of Japanese medicine were trained in Germany.

Among the young scientists who studied in one of those colleges, there was Masamune, Hajime (1896-1959) who was particularly interested in the problem of glycoproteins from cartilage. Masamune graduated from Kyushu Univ. in 1921, but went to Harvard Univ. in 1929 and then to Univ. of Leipzig in 1930 to acquire a fresh knowledge of biochemistry. After coming back to Kyushu in 1931 he started to work on the metabolism of proteoglycans in mammals and soon succeeded in characterizing animal glucuronosidase, glucuronidase, glucosaminase, and acetylglucosaminidase (1934-36), which were really pioneering studies. Masamune promoted to the Professor of Hokkaido Univ. in 1934 and then Tohoku Univ. in 1942. In 1943, a pure form

of chondroitin sulfate was first prepared from nasal cartilage of whale, using Masamune-Ozaki's formalin method. They estimated its structure as (acetylgalactosamine-glucuronide sulfate). Levene had asserted that four carbohydrates are conjugated in chondroitin sulfate, but his idea was clearly denied by Masamune. Furthermore, he proposed the general concept of the structure of so-called glycoprotein and predicted the presence of $\mathrm{N}$-glycosidic linkage in some proteoglycans.

Soda, Tokuro and Egami, Fujio (Univ. of Tokyo) reported that squid and horseshoe crab cartilages contain over-suifated chondroitin sulfates, while chondroitin-6-sulfate isolated from sturgeon cartilage, posesses only 0.87 sulfate residues per repeating unit. Suzuki, Sakaru (Nagoya Univ.) showed that the over-sulfated glycosaminoglycan of shark cartilage contains most of the ester sulfate at position $\mathrm{C}-6$ of acetylgalactosamine residues with the remainder substituted at $\mathrm{C}-2$ or $\mathrm{C}-3$ of the glucuronyl units. Murata, Katsumi (Tokyo Univ. of Fine Arts) reported that similar over-sulfated polysaccharide was isolated from human aortic tissue. Suzuki's group also isolated chondroitinase- $\mathrm{ABC}$ and chondroitinase-AC from microorganisms, which were very useful tool in the identification of trace amounts of chondroitin 4and 6-5ulfates in mixtures with other glycosaminoglycans. Testicular hyaluronidase was detected by Yoshizawa, Zensaku (Tohoku Univ.). Seno, Nobuko. (Ochanomizu Women's Univ.) reported that chondroitin 4-sulfate, chondroitin 6-sulfate, keratan sulfate, and hyalulonic acid were detected in cartilaginous tissue and that sulfate to disaccharide ratios of keratan sulfate from whale cartilage varies from $0.75-1.8$. She also found that keratan sulfate contains some minor carbohydrates such as fucose and sialic acid. In whale cartilage sialic acid has been identified as N-acetylneuraminic acid. She found that glycosaminoglycan content tends to be lower in articular cartilage than in most other cartilages.

Concerning biosynthetic pathways of proteoglycans, Suzuki and Strominger found that sulfate is first activated and transferred to the acceptor and that the activated PAPS is formed from inorganic sulfate in a two-step process. Suzuki's group then isolated from squid cartilage a sulfotransferase exhibiting the unique property of catalyzing the introduction of sulfate into position $\mathrm{C}-6$ of a $\mathrm{N}$-acetylgalactosamine moiety already bearing a sulfate residue at position C-4. Kimata, Koji (Aichi Medical Univ.) isolated nascent chondroitin sulfate attached to the Golgi membranes of chondrocytes. Kimata's group recently isolated cDNA clones encoding the core protein of proteoglycanL,b $(P \mathrm{G}-\mathrm{Lb})$, which has been shown to be preferentially expressed in the zone of ossifying area of the developing chick embryo cartilage. The homology analysis revealed that chick $\mathrm{PC}-\mathrm{Lb}$ showed a higher homology to human osteoglycin, formerly called osteoinductive factor, OIF. Kimata's group then identified $\mathrm{CDNA}$ clones of proteoglycan-M (PG-M), a large chodroitin sulfate proteoglycan expressed in the pre-chondrogenic condensation area of the developiong chick limb buds. The sequence analysis showed that PG-M 
showed a high homology to corresponding domains of a human fibroblast large chondroitin sulfate proteoglycan, versican. Therefore, they suggested that versican might be one of the multiple forms of PG-M.

Kimata's group also found the absence of proteoglycan core protein in cartilage from cartilage matrix deficiency mouse (cmd). Sugahara, Kazuyuki (Kobe Pharmaceutical Univ.) detected the defect in PAPS formation in brachymorphic mice. They represent examples of mutations that affect cartilage-specific macromolecules at two levels of the synthesis of proteoglycans, that is, sulfation (brachymorphism) and core protein (cartilage deficiency).

As chondroitin sulfate or hyaluronic acid gradually found a larger market, these commercial preparation became popular materials for the study of glyco-conjugated compounds and various related enzymes in biochemical laboratories. In parallel with these fundamental studies, there has been much work in Seikagaku Kogyo Co. and other inductries, using bovine and whale cartilage.

Ogata, Tomosaburo (Univ. of Tokyo) proposed a salivary gland endocrine theory in 1935. His associates observed that the active principle of extracts of the salivary glands of young beef cattle provided a hormone-like substance that they called "Parotin". This substance lowered the serum calcium levels in rabbits by approximately $15 \%$. Enhancement of the calcification of teeth and bones was another important effect resulting from its administration. Ito, Yosoji then isolated active principles in the form of homogeneous proteins having biological activities similar to those of parotin from bovine, porcine, and equine submaxillary glands, from human saliva, and also from human urine. Parotin generally acts on the mesenchymal tissues, especially the hard and connective tissues, to promote their development and growth.

The primary diseases resulting from parotin deficiency in humans are shown to include chondrodysplasia fetalis, Kashin-Beck's disease (endemic in Northeastern China), the endemic diseases occurring in the volcanic districts in Japan, arthritis deformans, and spongylitis deformans. Parotin was confirmed to be effective in compensatory therapy for the diseases. Endo Hiroyoshi and Ito, $Y$., using chick embryo femora cultures, demonstrated the effectiveness of parotin in promoting longitudinal growth and calcium deposition of bone, and suggested that parotin might directly stimulate some hard tissue development sites in vivo. Since then, Endo's group performed extensive studies on cartilage metabolism using tissue and cell cultures. However, we regret extremely that the structure of the so-called parotin has not been characterized yet.

Hiyeda, Kentaro (Kurume Univ.) found that the administration of the extract from refrigerated 16-day chicken embryos into partially resected sites of rabbit or rat long bones stimulates the regeneration of bone and he named this active principle "Osteogemin" (1955). It would have been some premature form of BMP or FGF-like substance, when we think of it now.

\section{Plenary Lecture}

CaRtilage Matrix Molecules With ROLES IN TISSUE Homeost asis

Dick Heinegård, Department of Medical and Physiological Chemistry, Lund University, Box 94. S-221 00 Lund, Sweden.

The isolation and characterization of an increasing number of cartilage matrix macromolecules have provided means for identifying distinct compartments and functional units in the tissue. The molecular composition of these compartments is ratier different, albeit some of the inajor macromolecules are common to the different structures.

A major macromolecular constituent of cartilage extracellular matrix is aggrecan or the large aggregating proteoglycan. distributed throughout the tissue.The other major component is the collagen fibers made up of collagen II molecules with some additional type XI in the same fibers. These fibers have the highest abundance in the interterritorial matrix. They run in different directions, such that they are parallel to the surface in the superficial layer and perpendicular to the surface in deeper layers. The properties of the fibers are modulated by the presence of other molecules on their surface. These molecules include covalently bound collagen IX as well as the proteoglycans decorin and fibromodulin. These diverse molecules have the potential for bivalent action by binding to the collagen II fibers via protein-protein interactions as well as by other interactions between their glycosaminoglycan chain and collagen. This provides an opportunity for linking neighboring fibers. Thereby the effective length of the fibers is extended to provide much improved tensile properties of the tissue. This arrangement appears essential to counteract the swelling properties of the aggrecan molecules and in dissipating load throughout the tissue. Other molecules in the cartilage matrix include the pentameric cartilage oligomeric matrix protein (COMP or chondrospondin), with particular homology to the thrombospondin imolecules. albeit the five subutits (compared to three for thrombospondin) are shorter and only some $85 \mathrm{kDa}$. There are also distinct sequence differences and the COMP molecule shows a much more narrow tissue distribution. The functions of COMP, that is only detected in cartilage by immunoassay, have not been delineated, although data indicate that the protein can mediate cell binding and may play a role in repair processes of the marrix. Cartilage matrix contains a number of other molecules detected in cartilage only. Chondroadherin or the $36 \mathrm{kDa}$ protein contains the typical leucine rich repeat domain found in the small proteoglycans. Chondraadherin can mediate chondrocyte attachment, apparently via integrins. A novel $92 \mathrm{kDa}$ protein shows a unique testricted distribution to the middle portion of the articular cartilage. Cartilage also contains small amounts of proteins with more general disiribution between tissues. e.g. thrombospondin and fibronectin. A trimeric sightly basic protein (CMP), although only found in cartilage, is absent from articular cartilage and the intervertebral disc.

By studies of the functions of these matrix molecules, the functional toles of the tissue domains will be delineated.
The mechanism of endochondral ossification in growth cartilage remains unclear, and whether hypertrophic cartilage cells survive in the bone marrow cavity has been debated repeatedly. Shimomura, Yutaka reported that hypertrophic cartilage transplanted survives to become osteocytes.

Suzuki, Fujio graduated from the Dept. of Bio-Organic Chem., Osaka Univ. but was appointed Assoc. Prof. in the Dept. of Biochem., Faculty of Dentistry in 1966, and so started with Yoneda, Toshiyuki and Shimomura Y. to try some cell biological approach to the mechanism of endochondral bone formation in 1972. First, we found that cultured growth-cartilage cells have a marked osteogenic potential, forming differentiated colonies producing abundant proteoglycans and type II collagen in vitro (1975). We also found that parathyroid hormone (PTH) significantly enhanced proteoglycan synthesis in these cells (1976). This finding may be the first indication of a new role of PTH in differentiation of cartilage.

In 1972, Nevo, Z and Dorfman, A reported that exogenous proteoglycans extracted from bovine cartilage stimulate proteoglycan synthesis by cultured chondrocytes. Since then, many investigators have tried to identify such regulatroy factors in cartilage. In 1980, we found some somatomedin-like factors in fetal bovine cartilage, named cartilage-derived factor (CDF). In the mean-time, Klagsbrun, M. purified a cartilage-derived growth factor (CDGF) from neonatal cartilage. However, their CDGF was found to be identical to bFGF. Thus, although it has been suspected that factors produced by chondrocytes may regulate cartilage growth and expression, in the last 15 years or more, nobody has succeeded in characterizing an active principle. However, we at last succeeded in the purification and molecular cloning of a cartilage-specific growth modulating matrix component ( $25 \mathrm{kDa}$ glycoprotein) that functions in growth regulation of the differentiated cartilage cells, and stimulates DNA synthesis of cartilage cells in the presence of bFGF. We named this unique principle "Chondromodulin-I $(\mathrm{ChM}-\mathrm{I})$ ". In addition, $\mathrm{ChM}-\mathrm{I}$ inhibited the proliferation of vascular endothelial cells and tube formation These findings indicate that cartilage-specific ChM-I is bi-functional: modulates cartilage growth and shows angioinhibin function. We also identified another modulator, ChM-II, from the same source. The amino acid sequence of ChM-II (133 amino acid residues) was significantly homologous to the product of chicken promyelocyte-specific mim-1 gene whose transcription was directly activated by the v-myb oncogene product. ChM-II resulted in increases in both DNA and proteoglycan syntheses in cultured rabbit chondrocytes. However, ChM-II did not inhibit DNA synthesis of endothelial cells but stimulated the differentiation of osteoclasts. Therefore, cartilage-derived matricrine factor, ChM-II would be the first characterized naturally generated, oeteopoietic coupling factor in endochondral bone formation. 


\section{Structure and Function of Cartilage ECM 16A-1}

STRUCTURE AND FUNCTION OF PRECHONDROGENIC MESENCHYME PROTEOGLYCAN, PG-M

Koji Kimata, Tamayuki Shinomura, Kazuo Ito, Masahiro Zako, Minoru Ujita, Naomi Yamakawa, and Yoshihiro Nishida. Institute for Molecular Science of Medicine, Aichi Medical University, Nagakute, Aichi 480-11, Japan

PG-M, a large chondroitin sulfate proteoglycan, was for the first time isolated from chick limb buds (1) and has been shown to be one of major extracellular matrix matrix molecules of the condensation area of undifferentiated mesenchymal cells in limb buds (2). This molecule disappears with cartilage development in an inverse correlation to a dramatic increase of cartilage proteoglycan, aggrecan (2). Such a transient expression of $P G-M$ in limb bud suggests that the formation of a specific extracellular matrix may be necessary for the precartilage condensation process during skeletal cartilage development.

Cell adhesion is a crucial step that regulates a variety of cell behaviors such as cell differentiation and tissue tissue-specific cell function. Michael Sorlush has suggested that modification of cell morphology greatly affect chondrogenic phenotype expression. We previously showed that $P G-M$ had an inhibitory activity for various types of cell-adhesion to extracellular matrix molecules (anti-adhesion activity) and suggested important roles in modulating a variety of such interactions (3). Further, we have recently found that the activity could be due to chondroitin sulfate chains attached onto the core protein (4). These findings suggest that modification of the cellextracellular matrix molecule interactions by anti-adhesion activity of PG-M may be greatly involved in the condensation process for cartilage development as well as maintenance of cartilage functions.

As one of approaches to the evaluation of this possibility, we have first studied the CDNAs encoding the core proteins of chicken PG-M (5) and mouse PG-M. Protein homology analysis of the deduced amino acid sequences revealed the presence of a link protein-like domain at the N-terminal region and a set of domais at the C-terminal region which are composed of a complement regulatory protein-like domain, a lectin-like domain, and two EGF-like domains from the C-terminus. These domains showed an extremely high homology between chicken $P G-M$ and mouse $P G-M$ and to corresponding domains of human versican (6). In contrast, the chondroitin sulfate-attachment domain at

the middle region of the core protein showed no significant homology among them. In addition, we found that alternative splicing of two different exons (alpha and beta) for the chondroitin sulfate-attachment domain at the middle region generated four different forms of the PG$M$ core protein (PG-M(VO), PG-M(V1), PG-M(V2), and PG-M(V3)(see Fig.1) and human versican corresponded to one of short forms (PGM(V1)). The occurrence in the core protein of regions with such different characteristics, the evolutionary non-conserved and variable domains at the middle region and the conserved and constant domains at the $\mathrm{N}$ - and C-terminal regions suggests their distinctive and important functions. An another series of our experiments have shown that the N-terminal and the C-terminal regions function as the hyaluronan-binding domain and the oligosaccharide-binding domain, respectively. Those regions may contribute to the organization of $P G-M$ in the extracellular matrix so as to express its anti-adhesion activity. On the other hand, the variable chondroitin sulfate-attachment domain generated by the alternative splicing may contribute to a regulation of anti-adhesion activity of $P G-M$ which is due to the variation of the amount and/or number of chondroitin sulfate chains per core protein.

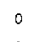

1000

2000 $3000 \quad$ a.a

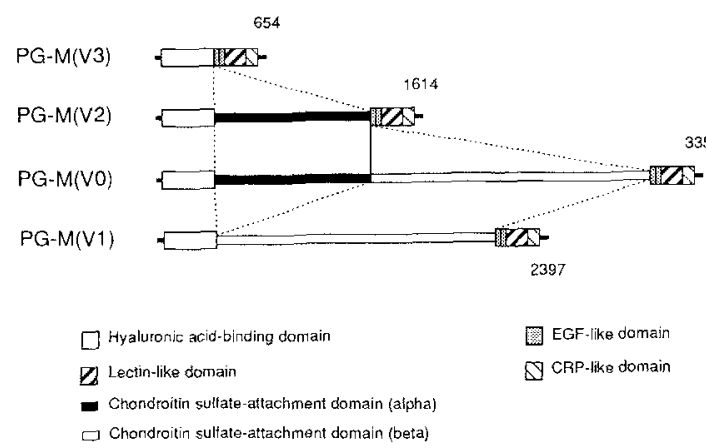

We have then investigated what forms of $\mathrm{PG}-\mathrm{M}$ core protein are involved in the mesenchymal condensation and whether or not mulciple forms of $\mathrm{PG}-\mathrm{M}$ core protein are regulated in a tissue-and/or time dependent manner. Northern analysis for RNA extracts from various tissue of mouse embryos at various stages using the different domain probes showed that PG-M(VO), the largest and chondroitin sulfate-attachment site-richest form of $P G-M$, is predominant in limb buds, and also suggested a tissue- and time-dependent variation in the expressions of PG-M multiform. It is likely, therefore, that the antiadhesion activity of $\mathrm{PG}-\mathrm{M}$ may vary in spatio-temporal manner, due to the difference in the amount and/or number of chondroitin sulfate chains per core protein and, in limb buds PG-M(VO) possibly with the highest anti-adhesion activity may cause a great change in the mesenchymal cell morphology which is essential for the onset of chondrogenic phenotype expression.

We have recently shown abnormal expression of $P G-M$ in human osteoarthritic cartilage (7) and also in a chicken model of experimental osteoarthritis. Staining with antibodies against the alternatively spliced domains indicated that osteoarthritic chondrocytes synthesized $\mathrm{PG}-\mathrm{M}(\mathrm{VO})$, suggesting the reappearance of immature cartilage phenotype. Therefore, it is also likely that the formation of an embryonic extracellular matrix comprising PG-M may cause some of abnormal characteristics of osteoarthritic chondrocytes.

References

(1)Kimata, K., et al. (1986) J. Biol. Chem. 261, 13517-13525

(2)Shinomura, T., et al. (1990) Anat. Embryol, 181, 227-233

(3)Yamagata, M., et al. (1989) J. Biol. Chem., 264, 8012-8018

(4)Shinomura, T., et al. (1993) J. Biol Chem,, 268, 14461-14469

(5)Sugiura, N., et al. (1993) I. Biol. Chem., 268, 15779-15787

(6)Zimmermann, D. R., \& Ruosiahti, E. (1989) EMBO J., 8, 2975

2981

(7)Nishida, Y., et al. (1994) Osteoarthritis \& cartilage, 2, 43-49

\section{A-2}

\section{STRUCTURAL STUDIES ON THE NOVEL SULFATED TETRASACCHARIDES ISOLATED FROM KING CRAB CARTILAGE CHONDROITIN SULFATE K \\ DEMONSTRATION OF 3-O-SULFATED GLUCURONIC ACID}

Kaznyuki Sugaharal, Yukako Tanakal, Shuhei Yamada', Hiroshi Kitagawal', and Nobuko Seno ${ }^{2}$

1Deparnment of Biochemistry. Kobe Plarmaceutical University, Kobe 658 , and 2Department of Chemistry, Ochariomizu University. Tokyo 112, JAPAN.

It has been increasingly evident that chondroitin sulfate (CS) proteoglycans of cartilage are dynamic components which play a multitude of key roles in the normal physiology of cartilage tissues and regulate the biological processes such as cell migration and recognition, extracellular matrix deposition and morphogenesis. Preliminary chemical analyses indicated that unlike CS of many other cartilages, CS K isolated from king crab cartilage seems to contain 3-O-sulfated glucuronic acid residues (1). This novel structure is known to form the unique carbohydrate epitope in nervous tissles, which is recognized by HNK-1 monoclonal antibody (2). During the course of the systematic structural studies of CS from various tissues $(3.4)$ we isolated two tetrasaccharides from CS K after hyaluronidase digestion. The analysis by degradation enzymes and $500 \mathrm{MHz}$ H-NMR unambiguously revealed 3-O. sulfated glucuronic acid residues in these tetrasaccharides. [Methods] CS K was exhaustively digested with sheep testis hyaluronidase. The digestion was performed by using $3.0 \mathrm{mg}$ of the enzyme and $30 \mathrm{mg}$ of $\mathrm{CS} \mathrm{K}$ in a total volume of $2.0 \mathrm{ml}$ of $0.15 \mathrm{M} \mathrm{NaCl} / 0.05 \mathrm{M} \mathrm{NaH} 2 \mathrm{PO}+\mathrm{pH} 6.0$ at $37^{\circ} \mathrm{C}$ for $18 \mathrm{hrs}$. Another $1.5 \mathrm{mg}$ of hyaluronidase was added thereafter and the incubation was continued for $7 \mathrm{hrs}$, and then the reaction was terminated by heating at $100^{\circ} \mathrm{C}$ for $1 \mathrm{~min}$. The digest was treated with trichloroacetic acid, neutralized with $1 \mathrm{M} \mathrm{Na} \mathrm{CO}_{3}$, lyophilized and reconstituted in water. The obtained oligosaccharide fraction was subjected to gel filtration on a column of Bio-Gel P10 using $1 \mathrm{M} \mathrm{NaCV} / 10 \% \mathrm{EtOH}$ as eluent. The separated oligosaccharides were pooled, desalted by chromatography on Sephadex G-25, and further fractionated by HPLC on an amine-bound silica column. The $\mathrm{NaH}_{2} \mathrm{PO}_{4}$ concentration was increased using a linear gradient at a flow rate of $1 \mathrm{ml} / \mathrm{min}$ from 16 to 530 mM over $60 \mathrm{~min}$ (3). NMR spectra of the oligosaccharides purified by HPLC 
were measured with a Varian VXR-500 spectrometer at a probe temperature of 26 or $60^{\circ} \mathrm{C}$

[Results and Discussion] CS K was digested with testicular hyaluronidase and fractionated by gel filtration on a column of Bio-Gel P-10 into three peaks which corresponded to tetra-, hexa- and octasaccharides. In this study, the tetrasaccharide fraction was analysed. Subfractionation of the tetrasaccharide fraction by HPLC yielded two major peaks (peaks B-5 and B-8) accompanied by several Fig.

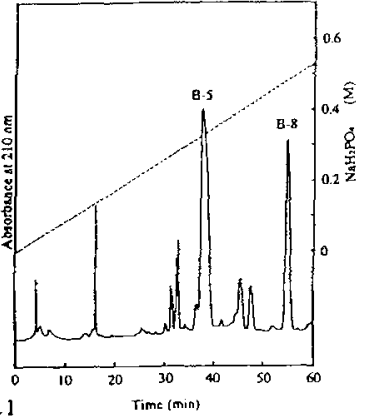
minor peaks as shown in $\mathrm{Fig}$. 1. These two major peaks were subjected to chondroitinase $\mathrm{ACII}$ and chondro-4-sulfatase digestions followed by $1 \mathrm{PLC}$ analysis, respectively. Peak B-5 was degraded by chondroitinase ACII into $\triangle \mathrm{Di}-4 \mathrm{~S}$ and a unique saturated disulfated disaccharide, and both resultant disaccharides were sensitive to 4 sulfatase. In contrast, peak B-8 was resistant to chondroitinase $\mathrm{ACII}$ although one sulfate group was removed by 4 -sulfatase digestion. NMR spectra of the peaks B-5 and - 8 oligosaccharides revealed that the compounds in these two peaks contain the following structures with novel 3-0-sulfated glucuronic acid residue(s). In the structural formulas $3 \mathrm{~S}$ or $4 \mathrm{~S}$ represents 3-or 4-sulfate group, respectively.

B-5: GlcA(3S) $\beta 1-3 G a l N A c(4 S) \beta 1-4 G l c A \beta 1-3 G a I N A c(4 S)$

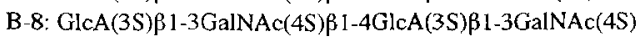

The variation in these two structures may indicate that in the biosynthesis 3 sulfation of GicA takes place after 4-sulfation of GalNAc residue. It remains to be determined whether these unique structures exist in mammalian tissues and what biological roles they play.

[Ref.] 1) Seno, N., \& Murakami, K. (1982) Carbohydr. Res.. 103, 190-194. 2) Ariga, T., Kohriyama, T., Freddo, L., Latov, N., Saito, M.. Kon, K., Ando, S., Suzuki, M., Hemling, M.E., Rinehart, K.L., Kusunoki, S., \& Yu, R.K. (1987) J. Biol. Chem., 262, 848-853. 3) Sugahara, K., Ohi, Y., Harada, "T., de Waard, P., \& Vliegenthart, J.F.G. (1992) J. Biot. Chem. 267, 60276035. 4) Sugahara, K., Shigeno, K., Masuda, M., Fujii, N., Kurosaka, A., \& Takeda, K. (1994) Carbohydr. Res., 255, 145-163.

\section{$16 \mathrm{~A}-3$}

FTBROCHONDROCYTES OF HUMAN KNEE MENISCUS SYHTHESIZE AGGBEGA AND TYPE II COLLAGEN

Takaaki Ianaka, katsuyuki fujid, Shigaku Sai, foshio kumagae and Kagebisa Murota.

Departaent of arthopaedic sargery, dikei bnituersity sahool of Hedicine, Tokyo 105 dapan.

\section{ATROSOCTION}

The meaisci of the hurati kne joint are located betreen the fencral condyles and the tibial plateau such a localization results in the menisci being sutiected to compressive forces during height-bearing. it is known that tuan meniscal cells were shofin to synthesiae cartilage-like proteoglycan (1). Hokever. netabuliso of huan mens cal fibrochondrocytes bave not been sell investigated. The present study nas andertaken in order to determine whethe thata measical cells synthesize ard express cartilage specific proteoglycan, aggrean and type ll collagen. in addition, the response to meniscal cells to TGFias determined in comparison with hyaline cartilage chond rocytes.

\section{BATERISLS AND HETHODS}

yuma knee articalar cartilage and medial arobcus were dissected from the amplated legs Cartilage slices was obtained foofemoral condyles. and redial meniscus was cleaned of soft tissues. ild ide part of meniscus ras divided into tho part (outer $1 / 3$ and inner $2 / 3$ ) considering the differenca in vasular suphly. Cartilage and meniscus bere

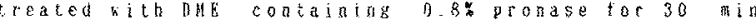
folloked oy 0.da collagenase treatment for 90 min. thondcocytes and meniscal cells were cultured either in dish or agarose. The cells were labelled tit 15 so. or tc-probine, and labelled cell mediur was nsed for Troteoglycan or collagen synthesis and non-labelled median nas used for liestern blot analysis. Cells were ased for extraction of total RNA. OLigonucleotides i zoner isgothesized based on the hum aggrecan chan i2) And type II collagen cBNa were used for do blot or liorthern blot hybridization. Furtheroore, indunobistochedical aralysis vas a lso performed.

B) IS LLTS

ffter one week in monulayer culture, 355-proteothycan synthesis of meniscal cells from the inner $2 / 3$ part kas 10 to 20 ghigher than that from the outer $1 / 3$. A teer six weeks in anoliyer culture proteoglycan syathesis of both cells was found to remarkabiy decrease. In contrast, after six beeks in agarose culture, teritorial cegjon of cells aas strongly

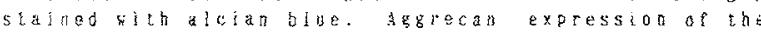
men iscal cells from the inner $2 / 3$ part was approxinate ly $25 \%$ of that of chondrocytes. In the presence of TGF- $\beta$ aggrecan expression of meniscal cells aas up regulated in a dose-dependent maner as well as chondrocutes, and proteoglycan synthesis was almost pararell to mal levels ( Fig. !).

rataicollagen synthesis of meniscal cells from the llner $2 / 3$ part was not different from that from the outer 1/3. Western blat analys is showed that type II collagen has syathesized from meniscal cells and the anount has decreased after a long tera cultare ( Pig. 2). Expression of type II collagen was also recognized by innuohistochenjcal analysis. Anti-type II collagen ancibody staining shomed that pericellular region and a part of extraceliglar mateig liere yositive. This staining pattern bas alnost consistent Ii. th alcian blue staining.

\section{B. ISCLSSTON}

peyiousty it is reportest that the anount a Eycosaninoglycans in meniscus was approkinately lo w op that ia hyaline cartilage (3). The present study showed that the amount of 35s-proseoglgcan synthesized by cells from the inter $2 / 3$ part was sreater than that from the outer $1 / 3$; this value was approximately 30 th of hondrocytes. The expression of aggrecan on lis bas consistent bith ss $s$-incorporation These data indicate bat meniscal cells irom the inner z/3 part. is more chondrocytic. In additioll in the piesence of ThP - $B$ proteoglycan synthesis kas stimulated is a dose-dependent ananer. Thus, hullar aenisea cells from the inner $2 / 3$ partare like chondrocytes

in terms of their expression of aggrecat and the response to TGF- $B$. The present studg also shoued that hype II collagen as expressed from hua a a a iscal cells and ras decreased after a lung term culture. This is a yigisar phenomenon found i n chondrocytes during dediferentiation. Type li coliagen syothesis of $\pi$ eniscal cells relative to chondracytes was less than aggrecan syothesis. Howeper, pericellular tegion and extracellular atrix stajned with type II eollagen atibody yas also staned uth aleian blae. le is showin that human oniscal cells express botbeggracan and type II collagen but expression type Il collagen lias less.
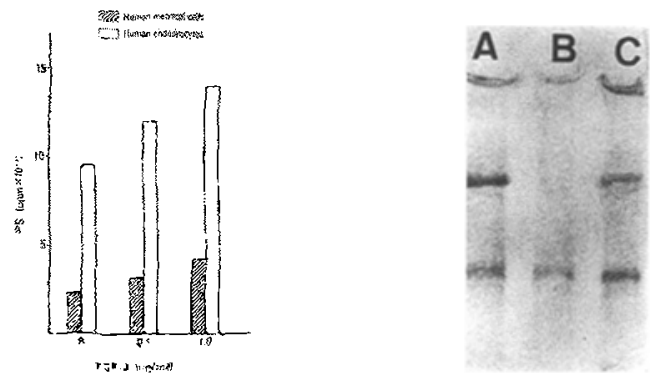

F 35,1

i.g. 2

Fig. 1. The effect of pag-B on proteoglycat syathesis

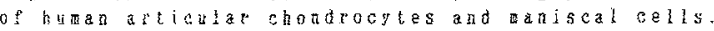

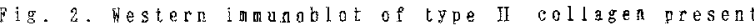
in the media of monolayer calture. (A) chandrocytes. (B) meniscal cells, 4 beeks. (C) a entscal cells, 1 week

\section{BEFERERE}

(1) Roughiey y.P.et a $1, \ldots(1981)$ gincher, J, 197, $77-83$

(2) Doege B.J.et al, (1991) J Biol Chen, 256,894-902

(3) Arnozk S.et al., (1988) penlscus,487-53? 


\section{Normal and Pathologic Metabolism of Cartilage 16P1-1}

\author{
CURRENT CONCEPTS OF AGGRECAN CATABOLISM
}

John D. Sandx, Kelli A. Garcia, John T. Gordy and Anna H.K. Plaas. Shriners Hospital for Crippled Children, Tampa Unit, and College of Medicine, University of South Florida, Tampa Florida, 33612, U.S.A.

Introductlon

Aggrecan is the major space-tilling proteoglycan of articular and growth cartilage matrix. The bulk of the mass of the aggrecan molecule is provided by its substituent chondroitin sulfate (CS) which, due to electrostatic repulsive forces between chains, provides the tissue with compressive resistance. Maimtenance of the aggrecan concentration in articular cartilage is therefore critical to tissue function. Modulation of the concentration and structure of aggrecan in the growth plate matrix would also appear to be a critical feature of growth plate maturation and matrix calcitication. The metabolism of aggrecan in cartilage is a function of the resident chondrocytes which have the capacity to syrthesize and assemble aggregates (each typically composed of $50-100$ aggrecan monomers bound non-covalently to link protein on a hyaluronan backbone) and also to degrade these multimeric structures. The mechanism by which chondrocytes catabolize aggregates is presently unclear and represents the central target of our investigations.

The aggrecan core protein has two globular domains at the $\mathrm{NH}_{2}$ terminus which are reterred to as $\mathrm{G} 1$ and $\mathrm{G} 2$ and these are connected by a proteolytically-sensilive segment known as the interglobular domain $(\mid \mathrm{GD}$ ). Analysis of aggrecan tragments trom a range of catabolic systems has indicated that a novel proteinase (aggrecanase), which cleaves the $\mathrm{Glu}^{373}$ - Ala ${ }^{374}$ bond of the interglobular domain (IGD) of aggrecan, plays a central role. Cleavage at this site separates the CS-substituted region of aggrecan from the G1 domain and so effectively destroys the function of the molecule. Such chondroitin sulfate-substituted catabolic products which result from aggrecanase action, and which initiate at $\mathbf{A l a}^{374}$, are released from articular cartilage explants, growth plate explants, and are present in human synovial fluids from both osteoarthritis and inflammatory joint diseases $(\mathbf{1 , 2})$.

in order to further study this activity we have developed a culture system in which different cells can be assessed tor their capacity to degrade aggrecan by the aggrecanasedependent pathway.

Methods:

Chondrosarcoma cell lines (LTC and Rx) were provided by Dr. James Kimura, Henry Ford Hospital, Detroit. The protocol for preparation of alginate bacs was essentially as described (3). Briefly, cells were entrapped at a concentration of $4 \times 10^{6}$ cells $/ \mathrm{mll}$ in $1.2 \%$ alginate beads

with exogenous 355 -labelled rat aggrecan aggregates. Beads (about 20 per culture) were maintained in $0.5 \mathrm{ml}$ DMEM/10\% FBS for $48 \mathrm{~h}$, switched to serum-free medium $(+/-1 \mu \mathrm{M}$ retinoic acid (RA)) and medium collections were made for 14 days and trozen after addition of protease inhibitors. Aggrecan products were chondroitinase-digested and porlions were fractionaled on SOS-PAGE (4-12\% gradient geis). Fragments were visualized on western blots by chemiluminescent detection with a peptide - specific antiserum to rat aggrecan G1 domain (antiCATEGQVRVNSIYODKVSL) and with an antiserum (anti-NITEGE, supplied by Dr. Jeff Weidner of Mesck, Fiahway, NJ) which specilicafly detects aggrocanase-generated Gi domain. Results :

We have previously shown $(4,5)$ that LTC cells in monolayer respond to RA addition by reilease of a $68 \mathrm{kD}$ product which represents the aggrecan $\mathrm{G} 1$ domain generated by aggrecanase action. When $8 x$ cells were maintained in alginate beads containing exogenous 355 -tabelled aggregates, and treated with retinoic acid, the cells responded catabolically by increased release of aggrecan fragmenis into the medium. Calculations based on the release curves indicated that the balt-life of radiolabelled agarecan in control beads was about 42 days and this was reduced to about 28 days in the presence of RA.
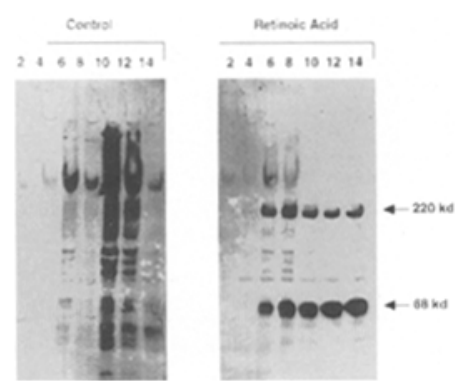

Western blot analysis of aggrecan fragments in medium from day 2 thru day 14 from parallel experiments (see Figure) showed that the pattern of immunoreactive fragments released was markedly altered by RA treatment. Control release products (left panel) were detected first on day 6 and were characterized by a high molecular weight aggrecan core species and a mixture of iragments of intermediate size. However, in the presence of RA (right panel), two major products were generated which were essentially undetectable in controls. Firstly, a $220 \mathrm{kD}$ species, which is also a major calabolic product of monolayer cutture (4). This product apparenily represents Gt-bearing aggrecan which has been truncated from the $\mathrm{C}$-terminal end of the core protein. Secondly, a $68 \mathrm{kD}$ product, which also reacted with the anti-NITEGE antisenum (not shown) and which therefore represents the $\mathrm{G} 1$ domain resulting from aggrecanase-mediated cteavage of aggrecan at the Glu 373 . Ala 374 bond

Conelusion :

The results show that $A x$ chondrocyres maintained in alginate beads under these conditions will respond catabolicafity to $R A$ treatment by degradation of aggrecan via an aggrecanase-mediated pathway. Moreover, the cells use this pathway to degrade aggrecan supplied to the beads exogenously. This cuture system should therefore facilitate the search for aggrecanase activity in different cell populations and also aliow for an evaluation of the effects of aggrecan substrate structure on the efficiency of the aggrecanase-mediated process.

\section{References:}

(i) Sandy J.D, et. al. (1991) J. Biol. Chem. 266, 8683-8685.

(2) Sandy J.D.et al (1992) J. Clin. invest. $89,1512-1516$.

(3) Guo J et al (1989) Conn. Tiss. Res. 19, 277-297.

(4) Sandy J.D. et al (1993) Trans. Orth. Res. Soc. $19,49$.

(5) Lark MW, Sandy JD et al (unpublished).

\section{$16 \mathrm{P} 1-2$}

PERICELLULAR MATRIX REMODELLING AND THE ROLE OF THE CHONDRON IN THE GENESIS OF OSTEOARTHRITIS

\section{Anthony Pogle.
Popartment of Anatomy, School of Medicinc, University of Auckland, 90214 , Auckland, New Zealand.}

INTRODUCTION

Articular cartilage plays a major role in joint mechanics, and is primarily responsible for the smooth transmission of compressive forces to the rigid underlying bone. Matrix integrity is critical for load bearing. and long term mechanical perturbation of the matrix is one of the key factors in the induction of osteoarthritic degeneration. Several studies now indicate the chondrocyte plays a key role in the initiation of matrix remodelling, a process involving the complex interaction of cytokines, growth factors, matrix metalloproteinases and tissue enzyme inhibitors. In particular, the degradation of pericellular type Ir collagen has been identified as one of the earliest recognisable structural changes to occur during matrix remodelling (1).

Previous studies have escablished the chondrocyte and its pericellular microenvironment represents the chondron, a natural micraanatonical unit of adult articular cartilage which can be extracted by the chondron, a natural micraanatontical unit of adult articular cartiage which can be extracted by
slow speed serial homogenisation (2). Immunohistochemical studies have characierised the slow speed serial homogenisation (2). Immunohistachemical studies have characierised the
heterogeneous composition of the pericellular microenvironment, and in particular the distribution of heterogeneous composition of the pericellular microenvironment, and in particular the distribution of
the minor collagens types VI and IX. In isolated chondrons extracted from normal articular cartilage, the minor collagens types VI and IX. In isolated chondrons extracted from nomal articular cartilage,
types VI and IX collagens are restricted to the pericellular capsule of the chondron (3). By comparison, histochemical analysis of chondrons isolated from osteoarthritic cartilages has identified structural and temporal changes which characterise the transition from a nomai chondron to a swollen chondrocyte cluster typical of osteoarthritic pathology (4).

METHODS

To better define the response of cartilage macrix components to degenerative remodelling, we examined changes in the distribution of collagen types VI and IX in five dogs euthanised for spontaneous to complete ebonation of bone in the centre of the plateau. Intact samples of cartilage and underlying bone were removed from the centre and periphery of each plateau. fixed in $4 \%$ paraformaldehyde for 1 hour, washed and the samples divided in cwo. One pottion was equilibrated in $20 \%$ DMSO, and stored frozen at $-20 \% \mathrm{C}$, prior to cryosectioning $310-25 \mathrm{\mu m}$. The other portion was mounted wet in a vibratome, and thick slabs of cartilage (35-100umi) prepared for confocal microscopy. Cartilage remaining on the

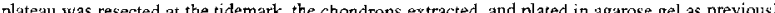

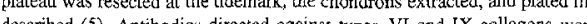
described (5), Antibodies directed against types VI and [X collagens were probed with a range of fluorescent or electron dense secondary antibodies, and the samples examined by light, confocal and transmission electron microscopy as pteyiously described (3).

RESULTS

Type VI Collagen: Testicular hyaluronidase digestion was an essential prerequisite for exposure of type VI epitopes, revealing a discrete pericellular distriburion in both unaffected (figure lat) and involved cartilue. By contrast, omission of the hyluronidase digestion produced variable results. In involved cartiage By contrast, omission ar he hy auronidase digestion produced variable results. In unaffected eartige from the periphery, no type Vr staining was observed. Conversely, in regions of surface fibrilation, or fissure formation, strong staining for type VI collagen was evident (figure $1 \mathrm{~b}$ ), while unaffected regions of the matrix remained unstained. The remodelling of pericellular type $\mathrm{VI}$ 
collagen was restricted to a 'reactive layer' characterised by the presence of chondrocyte clusters at the eroding surface. Type VI collagen content in this 'reactive' layer incressed as the microenvironment expanded to accommodate the continued cell proliferation, but remained almost exclusively associated with the surface of the chondrocytes (figure la, b). Osteoarthritic chondrons isolated from these samples provided superior images of the close inter-relationship between the chondrocyte and type VI during pericellular remodelling (figure $1 \mathrm{c}$ ).

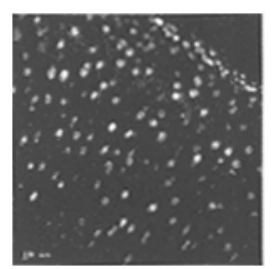

Figure ia

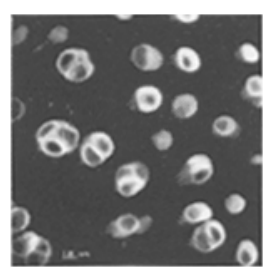

Figure $1 \mathrm{~b}$

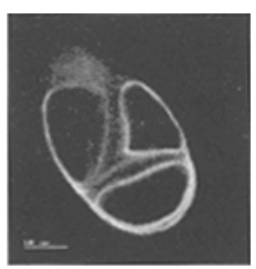

Figure lc
Type IX Collagen: Hyaluronidase digestion was also required to expose type IX epitopes, and patterns of staining similar to those described above were seen when enzyme extraction was omitted. However type IX collagen remodelling in the 'reactive' layer appeared distinctly different. First, there was an abrupt transition from discrete pericellular, to strons extracellular, staining at the junction between abrupt transition from discrete pericellular, to strong extracellular, staining at the junction between
normal cartilage and the advancing fibrilation front (figure 2a). Second, type LX remodelling coincided with expansion of the pericellular microenvironment and the initiation of chondrocyte division (figure 2b). Finalily, as the protiferating cell ciusters enlarge toward the eroding surtace, pericellular staining for type IX collagen was significantly reduced, while extracellular staining was substantially increased. Near the eroding articular surface, a matrix space completely devoid of type IX staining was typically observed between the weakly stained clusters and the intensely stained matrix (figure $2 \mathrm{~b}$ ). Isolated osteoarthritic chondrons reflected this spectrum of type IX collagen remodelling (figute $2 c$ ). and the progressive restriction of type IX collagen staining to a residual calyx typical of chondrocytes at the eroding surface (figure $2 \mathrm{~b}$ ).

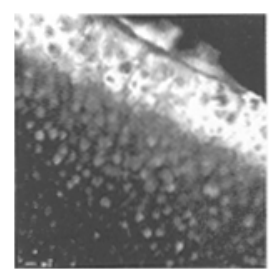

Figure $2 \mathrm{a}$

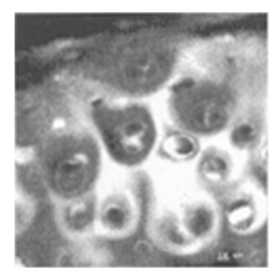

Figure 2b

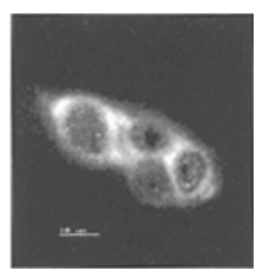

Figure $2 c$
DISCUSSION

This study has shown that the 'minor' pericellular collagens, type VI and type IX, are differentially affected during the matrix remodeling which accompanies spontaneous canine osteoarthritis. It also demonstrates that minor collagen remodelling was limited to a 'reactive' matrix layer between the eroding articular surface and the advancing margins of fibrilation or fissure involvement. Invariably, remodelling of both collagen species was associated with the initial cell division and the continued proliferation of chondrocytes within this 'reactive' layer. Outside this involved surface region, the proliferation of chondrocytes within this 'reactive' layer. Outside this involved surface region, the
distribution of types VI and IX collagens appeared unaffected, and they were typically concentrated in the chondron with little staining in the bulk extracellular matrix.

Within this 'reactive' layer, the pericellular remodelling of types VI and IX collagens appeared quite different. At its advancing edge, recruitment of new chondrons into the degenerative processes was accompanied by expansion of the pericellular microenvironment and increased staining for both collagen species, even in the absence of hyaluronidase digestion. Dividing cells initially retained a portion of the expanded microenvironment, but as chondrocyte proliferation proceeds to cluster formation, pericellular type IX coliagen hecame restricted to a narrow calyx around each cell, while extracellular type IX collagen increased significantiy. By contrast, the bulk of type VI collagen remained extracellular type IX collagen increased significantly. By contrast, the bulk of type VI collagen remained
closely associated with the cell surface during cluster formation, but it too was ultimately restricted to closely associated with the cell surface during cluster formation,
a narrow calyx around each chondrocyte at the eroding surface.

Type IX is a FACIT collagen involved in limiting the diameter of heterotypic collagen fibrils composed of types II and XI collagens (6). These fine heterotypic fibrils provide the architectural integrity of the chondron, but are vulnerable to attack by a range of matrix metalloproteinases, notably stromolysin (7). The synthesis of metalloproteinases is up-regulated by IL-1 (8), and it is probable that the reduction in pericellular type IX collagen results from metalloproteinase induced catabolism. Simila type IX remodeling has recently been induce in isolated chondrons cultured in the presence of IL (work in progress). The high extracellular concentration of type IX is more difficult to explain, and further work is required to establish if it is the result of increased type IX synthesis, or increased concentrations of catabolic type IX fragments trapped in the bulk extracellular matrix.

In contrast, type VI collagen is not degraded by IL-1 induced metalloproteinases, but rather, by the serine proteinases, typically associated with the inflammatory response which accompanie osteoarthritis (9). While type VI collagen is obviously remodelled in the 'reactive' layer, it remains closely associated with the swollen microenvironment and the chondrocyte calyx, with little staining in the bulk matrix. These results suggest that serine proteinase could regulate type VI collagen remodelling to ensure the integrity of the expanding cell cluster, and the continued survival of individual chondrocytes confined within.

On the basis of these and other studies (4), a three phase hypothesis for chondron degeneration has been developed. First, cytokine-induced disruption of pericellular collagens allows expansion of pericellular proteoglycans causing the chondron to swell. Second, reduction in the steric hindrance exerted by degraded fibrillar collagens stimulates the progenitor chondrocyte to divide. Finally, physicochemical changes in the pericellular microenvironment promote the cartilage catabolistn and chondrocyte proliferation typical of osteoarthritic cartilage pathology. The mechanisms responsible for the initiation and progression of this pericellular remodelling have yet to be fully elucidated.

Supported and funded by the Health Research Council of New Zealand. Antibodies supplied by Drs S. Ayad and D. Hartman are gratefully acknowledged.

(1).J. Clin. Invest. 83: 440, 1989. (2). J. Orthop. Res. 6: 408, 1988. (3). J. Cell Sci. 113: 1101, 1992.(4), Arth. Rheum. 43: 22, 1991. (5). J. Histochem. Cytochem. 39: 1175, 1991. (6). Cutr. Opin. Struct. Biol. 3: 430, 1993. (7). J. Biol. Chem. 266: 5625, 1991. (8). Matrix 13: 95, 1993. (9), Biochem. Biophys. Res. Comm. 191: 1230, 1993.

\section{P1-3}

A PERSPECTIVE ON METALLOPROTEASE REGULATION IN GROWTH PLATE PHYSIOLOGY

David S. Howell, Ofelia E. Muniz, Zvi Schwartz *, Barbara D. Boyan *, and David D. Dean*. GRECC, V.A. Medical Center and Univ. of Miami, Miami, USA and "Department of Orthopaedics, University of Texas Health Science Center, San Antonio, USA.

The extracellular matrix of calcifying growth plate cartilage (longitudinal septa) are an intricate mesh of collagen networks, proteoglycans and multiple other proteins, which we believe must undergo metabolic changes before calcification can occur. Most of these changes occur opposite the hypertrophic cells, which through enlargement and elongation can accelerate longitudinal bone growth (1). During relentless growth plate advancement in the rat, elimination of over $40 \%$ of the extracellular proliferative cell zone matrix occurs within a few hours to accommodate the $5-10$ fold enlargement of chondrocytes (2). Proteolytic enzymes accomplish these processes, as part of degradative casades (2). Breakdown of the septal extracellular matrix involves many proteolytic enzymes and a variety of substrates. Most of these enzymes belong to 1 of 2 families, the cartilage serine proteases, e.g., plasminogen activator (UPA) or other serine proteases and the matrix metalloproteases (MMPs), (3) in cartilage. At least 9 different MMPs have been reported. Prominent among these are coliagenase stromelysin, gelatinase $A$ or $72 \mathrm{~K}$ gelatinase, and these are the principal enzymes studied in our laboratory. We have focused on accelerated collagenolysis by interstitial collagenase, as well as activity of stromelysin and gelatinase $A$ - the components detected by acid and neutral metalloprotease assays respectively (4). The catalytic activity of these proteases is tightly regulated, and they are secreted as inactive proenzymes. The procollagenase appears from our studies to be regulated predominately by interleukin $1 \beta$ rather than interleukin $1 \alpha$ or TNF $\alpha$ (5). The process is independent of the presence of vitamin D metabolites in regard to adequate cell enlargement and matrix removal capability (6). However, increased matrix degradation can occur in the presence of phosphate deficiency by increased active collagenase and suppression of TIMP in the presence of $24,25(\mathrm{OH})_{2} \mathrm{D}_{3}$ (7). This phenomenon is not observed in the presence of calcium deficiency and adequate phosphate level. The activation of the collagenase must occur at the plasma membrane surfaces, because micropuncture fluid assays of fluid opposite hypertrophic cells shows the presence of latent, but no active collagenase $(2,8)$. We found that cultured growth cartilage cells chondrocyte plasma membranes lack the presence of plasminogen activator at sites where activation of collagenase would be essential in hypertrophic cells, but was present in matrix vesicle membranes at sites where capillary invasion could provide the substrate piasminogen. The presence of plasminogen activator (PA) neutral metalloprotease in matrix vesicles in a totally active form suggest that plasmin is an MMP activator there. Hypothetically, a new metalloprotease

discovered in cancer cells, MTMMP (Sato, $H$. et al. (1994) Nature 370:61-65), a membrane bound metalloprotease could account for activation of collagenase at hypertrophic cell sites where the plasminogen fails to penetrate the cartilage. Upregulation of procollagenase and stromelysin in RNA and downregulation of TIMP 1 and 2 mRNA have been recently demonstrated in rat growth plate chondrocytes (7). The ultimate fate of proteoglycan and their role in minerafization remain in dispute. Our view is that proteoglycan may function both for calcium storage (9), and for inhibition of mineralization (9). The presence of proteoglycan including some stored calcium in the form of "tightly knit" aggregate molecules in a gel of $50 \%$ concentration of dry weight estimated from the authors' previous studies (9) would make diffusion of ions impossibly slow, unless channels to the available capillary lymph are opened for fast ion exchange. The finding of a complete proteolytic system in cultured matrix vesicles seems to support the hypothesis that following the breakdown of the phospholipid membranes by increased phospholipase A2, and release of active proteases from the vesicles of crystal proliferation and expansion of mineral phase ensues.

\section{References}

1. Hunziker, E.B. Schenk, R.K., \& Cruzorne, L.M. (1987) J. Bone Joint Surg. 69A: $162-173$.

2. Dean, D. Muniz, O.E., Berman, I., Pita, J.C., Carreno, M.R., Woessner, J.F. Jr., \& Howell, D.S. (1985) J. Clin. Invest. 76:716-722.

3. Woessner, J.F., Jr. (1991) FASEB J. 5:2145-2154.

4. Wilhelm, S.M., Shao, Z.H., Housley, T.J., Separak, P.K., Baumann, A.P. Gunja-Smith, Z. \& Woessner, J.F., Jr. (1993) J. Biol. Chem. 268:21906 21913.

5. Arsenis, C., Dean, D.D., Muniz, O.E. \& Howell, D.S. (1990) Trans. Orthop. Res. Soc, $15: 159$.

6. Dean, D.D., Muniz, O.E., \& Woessner, J.F., Jr. (1990) Matrix 10:320-330. 7. Grumbles, R.M., Dean, D.D., Muniz, O.E., Masse, P.G., Roos, B.A. \& Howell, D.S. (1994) Trans. Orthop. Res. Soc. 19:418.

8. Dean, D.D. Muniz, O.E., \& Howell, D.S. (1989) Matrix 9:366-375 9. Howell, D.S \& Dean, D.D. (1992) in Disorders of Bone and Mineral Metabolism (F.L. Coe, M.J. Favus, Ed.), pp. 313-353. Raven Press, New York.

10. Dean, D.D., Schwartz, Z.V.I., Muniz, O.E., Gomez, R., Swain, L.D., Howell, D.S. \& Boyan, B.D. (1992) Bone Min. 172-176. 
16P2-1

\section{STIMULATION OF TIMP-1 PRODUCTION BY ONCOSTATIN M IN HUMAN ARTICULAR CARTILAGE}

\section{Masayuki Shimmei and Osamu Nemoto}

Department of Orthopaedic Surgery, National Defense Medical College, Saitama 359 , JAPAN.

\section{[INTRODUCTION]}

Oncostatin M (OSM), 28-kDa glycoprotein, is a newly characterized cytokine which shares structural and functional homology to IL-6 1). It is well known that tissue inhibitor of metalloproteinase -1 (TIMP-1) is a potent inhibitor of activated matrix metalloproteinases (MMPs) and involved in the control of extracellular matrix degradation in chondrocytes 2 ). Furthermore, the production of MMPs and TIMP-1 have been thought to be regulated by various cytokines 3). Since TIMP-1 expression has been shown to be up-regulated by IL-6 4), it should be meaningful to study the effects of OSM on TIMP-1 production by chondrocytes.

\section{[MATERIALS AND METHODS]}

Patella cartilage from 6 cadavers were used as tissue and cell culture Cartilage slices were incubated in the DMEM containing $2 \%$ FBS with various cytokines for 10 days. For chondrocyte culture, finely diced tissues were treated with $0.4 \%$ pronase $E$ for 1.5 hours, followed by digestion with $0.025 \%$ collagenase $P$ for over night. Dissociated cells were seeded at the density of $5 \times$ $10^{5} \mathrm{cells} / \mathrm{ml}$ and cultured with DMEM $+10 \%$ FBS. After confluency, cultured medium was changed to DMEM + 2\% FBS and stimulated with cytokines for 48 hours. Both tissue and cell culture supernatant were tested for MMP-3 and TIMP- 1 production by EIA kits. As for the production of MMP-1,2 and 9 western blot analysis was performed by using anti-human MMP-1,2 and 9 monoclonal Ab, respectively. To sludy the effects of OSM on TIMP-1 mRNA expression, northern blot analysis was prepared by standard techniques and hybridized with human TIMP-1 CDNA probe.

\section{[RESULTS}

As shown in Fig.1, OSM stimulated TIMP-I production in a dose dependent manner. Enhancement of TIMP-1 production was evident at $1 \mathrm{ng} / \mathrm{ml}$ and further elevated at $10 \mathrm{ng} / \mathrm{ml}$ and $50 \mathrm{ng} / \mathrm{ml}$ of OSM. Stimulatory effects in TIMP-1 mRNA expression were also confirmed by northern blot analysis. In contrast, OSM did

not induce MMP-1,2,3 and 9 production in both tissue and cell culture. When comparing the effects of OSM with other cytokines such as IL-1, IL-6, LIF and

TGF-beta on TIMP-1 production, TIMP-1 mRNA expression was substantially stimulated by OSM, TGF-beta and somewhat less by IL- 6 . [DISCUSSION]

We demonstrated here that OSM stimulated TIMP-1 production, showing the same degree as that of TGF-beta, whereas the production of MMPs were not changed by OSM. These findings lead us to speculate that OSM might have possible roles in the modulation of cartilage matrix degradation, through induction of 'TIMP-1 production in chondrocytes.

\section{[ACKNOWL EDGEMENTS]}

We thank Prof. Seiki (Kanazawa Univ. ) for kindly providing human MMPs , TIMP-1 cDNA probes and Fuji. Chem. Ind. Ltd. for supplying MMP-3 and TIMP-1 EIA kits.

\section{[REFERENCES]}

1. Rose, T.M. and Bruce, A.G. (1991) Proc. Natl. Acad. Sci. U.S.A. 88: 8641 8645 .

2. Pelletier, J.-P., F. Mineau, M.-P. Faure, and J. Martel-Pelletier. (1990) Arthritis Rheum. 33: $1466 \cdot 1472$

3. Shinmei, M., Masuda, K., Kikuchi, T., and Shimomura, Y. (1990) Semin. Arthritis Rheum. 4: 16-20.

4. Lotz, M. and Guerne, A. (1990) J. Biol. Chem. 266; 2017-2020

Fig. 1 Effects of OSM on TIMP-1 Production (cell culture)

\section{TIMP.1}

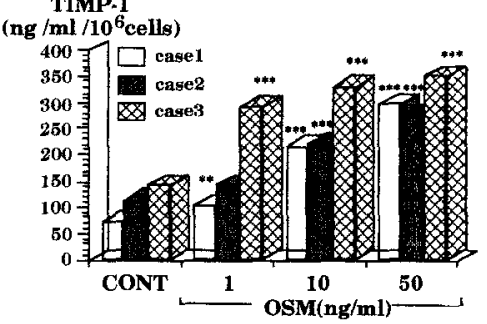

16P2-2

MATRIX METALLOPROTEINASES AND CARTILAGE DEGRADATION DURING INFLAMMATION

Karen A. Hasty, Tomohiko Hirose, Ken Kikuchi and Carlo L. Mainardi, Departments of Anatomy and Neurobiology and Medicine, University of Tennessee, Memphis, Tennessee, USA 38104 and the Department of Orthopaedic Surgery, Juntendo University, Tokyo, JAPAN

Using the animal model of collagen-induced arthritis, we have described two phases of cartilage matrix destruction; initial loss of proteoglycan followed by erosion of the underlying collagen matrix (1). Loss of collagen is felt to be the irreversible step in degradation of cartilage matrix. We have undertaken study of the primary structure of collagenase, the matrix metalloproteinase responsible for degradation of type II collagen, to define the structural determinants important in recognition and cleavage of its collagen substratc. To address this question, we generated truncated mutants of neutrophil collagenase ( $\mathrm{TrNC}$ ) with varying deletions in the carboxy-terminal (C. terminal) domain and chimeric molecules between neutrophil collagenase (NC) and stromelysin (Strom), and assayed the expressed enzymes against type I collagen and the general substrate, casein (2).

[Methods] The cDNAs of the mutants were cloned into a pCDNAI expression vector and transfected into $\operatorname{COS}-7$ cells. We tested enzymatic activity in the culture supernatants against type I collagen and the general substrate casein. The amount of the enzyme was normalized by Westem blot analysis with antiserum raised against a synthetic peptide of NC and by autoradiography of culture supernatants of COS-7 cells labeled with [35S]-methionine. To further define sequences critical for substrate recognition, chimeric enzymes were constructed by fusing cDNA representing the carboxy-terminal portions of stromelysin to the collagenase fragments representing the amino-terminal sequence. This allowed conservation of the cysteine loop at the carboxy terminus.

The development of chimeric metalloproteinases with and without collagenase activity allowed us to test the hypothesis that substrnte specificity, i.e. cleavinge of native type 1 collagen, is direcily related to stbstrate binding. To test this hypothesis, recombinan enzymes were incubaled with natjve reconstituled colligen fibrils at $22^{\circ} \mathrm{C}$ tor 45 minutes

and the bound enzyme quantitated using an ELISA technique. Substrate binding was assessed before and after incubation with aminophenyl mercuric acetate to detect differences in active and latent enzymes.

[Results] Significant reduction in enzymatic activity against type I collagen was seen with subsequent deletion of carboxy terminal sequences. The deletion of the four terminal amino acids including cysteine 464 resulted in significant reduction in collagenase activity. Cysteine 464 may stabilize a critical loop at the carboxyl end of the molecule by interacting with the cysteine at position 279 . Further deletion resulted in loss of substrate specilicity. TrNC 262 did not show any activity against type I collagen but degraded casein. This suggests that the catalytic region of the molecule remained intact and distinct from the site of substrate recognition. Chimera NC326 / Strom exhibited significant collagenase activity while NC258/Strom did not show any activity against type I collagen

Interestingly, all activated recombinant enzymes exhibited binding to collagen, although only two, wild type collagenase and NC326/Strom, had been shown to appreciably degrade the substrate. The latent wild type recombinant NC did not bind to collagen. By contrast, chimerae with or without collagenase activity bound to collagen in both latent and activated forms. The binding to collagen therefore did not seem to correlate with the ability to degrade collagen.

The binding of both latent and active enzymes led us to hypothesize that chimerate beating the carboxyl domain of stromelysin were binding to collagen in a nanner which differed ftom wild type coltagenase which bound only when active. To investigate this hypothesis, we quantitated the binding of the recombinant enzymes to colligen which had been completely digested with collagenase under conditions which preserved the native confirmation of the three quater and one quarter fragnents. Wild type NC bound insignificantly to collagenase derived collagen tragments while both chimerae with the stromelysin derived carboxyl terminal domain bound to collacen fragments.

[Discussion] Our data suggest that substrate-specificity for interstitial collagen is determined by a 62 amino acid sequence in the C-terninal domain of $\mathrm{NC}$ and is dependent upon the integrity of a disulfide-defined loop at the C-terminus for maximal activity. This suggests that collagen binding of the chimerae is related to the carboxyl teminus of stromelysin, does not correlate with collagenase activity and is not dependent on the 
presence of the cleavage site on collagen. By contrast, wild type collagenase does not bind signiticantly in its latent form, recognizing the collagen monomer only when activated. The binding to active enzyme is dependent on the presence of an intact cleavage site in the collagen, no doubt relating to the release of the processed substrate.

[Acknowledgments] This work was supported by grants from the National Insitutes of Health (Aj22603 and AR39166) and the Arthritis Foundation.

[Refereaces]

1. Hasty, K. A., Reite, R. A., Kang, A. H. and Stuart, J. M. (1990). Arth. Rheum. 33, 388-397.

2. Hirose, T., Patterson, C., Pourmotabbed, T, Mainardi, C. L. and Hasty, K. A. (1993). Proc. Natl. Acad. Sci. USA 90, 2569-2573.

\section{$16 \mathrm{P} 2-3$}

CARTILAGE-DERIVED INHIBITORS OF ANGIOGENESIS

Marsha A.Moses, Department of Surgery, Harvard Medical School and The Children's Hospital Medical Center, Boston, MA, 02†15, USA

Angiogenesis, the process of new capillary growth from pre-existing vessels, is important in a number of important physiological events, both normal and pathological. When it occurs under normal conditions, angiogenesis is a stringently controlled process. Under pathological conditions, these controls fail. There exist a number of serious diseases, characterized by persistent and deregulated neovascularization, which have recently been termed "angiogenic diseases", including a number of connective tissue pathologies (1).

Motivated by our interest in understanding the mechanisms underlying the control of angiogenesis, we have studied cartilage, an avasculartissue. We have demonstrated that cartilage contains a potent inhibitor of neovascularization in vivo using the chick chorioallantoic membrane assay and the rabbit corneal pocket assay (2). To understand the mechanism by which CDI (Cartilage-Derived Inhibitor) may exert its anti-angiogenic effect, we have tested it in a number of in vitro angiogenesis assays including those which measure capillary endothelial cell proliferation, migration, and capillary tube and sprout formation. The inhibitory activity of $\mathrm{CDI}$ in these systems will be presented in detail.

Interestingly, we have found that CDI is also an inhibitor of matrix metalloproteinase activities. These studies represent the first demonstration that a metalloproteinase inhibitor, with no other known biological activity, can inhibit angiogenesis. Further studies from our laboratory have demonstrated that cultures of scapular chondrocytes which were were established and maintained serum-free, produce an anti-angiogenic factor which shares the same biological activities as CDI (3).

We have recently become interested in understanding the role of $\mathrm{CDI}$

and its target metalloproteinases in the switch to the angiogenic phenotype. One of the model systems that we are utilizing is the development of chondrosarcoma, the vascularized tumor of cartilage. We have developed a system to study the transition from normal cartilage to chondrosarcoma in vivo and have also established cell lines representative of these various transition states for in vitro study as well (4). Data will be presented which suggest that one means of controlling the deregulated vascular growth characteristic of many angiogenic diseases may be at the level of the control of matrix metalloproteinase activity.

\section{References}

1. Folkman, J. and Klagsbrun, M. (1987) Science 235, 442-447.

2. Moses, M.A., Sudhalter, J. and Langer, R. (1990) Science 2488 , 1408-1410.

3. Moses, M.A., Sudhalter, J. and Langer, R. (1992) J. Cell Biol. 119 , 475-482

4. Moses, M.A. and Shing, Y. (1994) Biochem. Biophys. Res. Comm. $199,418-424$ 


\section{P1-1}

FURTHER CHARACTERIZATION OF A HUMAN CHONDROSARCOMA-DERTVED CHONDROCYTIC CELL LINE: HCS-2/8

Masaharu Takigawa', Kojiro Takahashi1, Tohru Nakanishi', Takako Hattori', Yusuke Kimura ${ }^{\dagger}$, Hai-Ou Pan ${ }^{2}$ Akihiro Kinoshita ${ }^{3}$, Kaoru Nakajima ${ }^{4}$. Fujio Yusuke Kimura, Hai-Ou Pan', Akihiro Kinoshita ${ }^{3}$, Kaoru Nakajima ${ }^{4}$, Fujio Suzuki ${ }^{4}$, Shintaro Nomuras, Tokutaro Okawa ${ }^{6}$ and Jing-de Znu', ${ }^{1}$ Dept. of Biochemistry, Okayama University Dental School, Okayama 700, JAPAN, 2Drug Discovery Research Laboratories, Hoechst Japan, Kawagoe 350-11, JAPAN
Depts. of 3Pediatric Dentistry and 4Biochemistry, Faculty of Dentistry and 5 Faculty Depts. of 3 Pediatric Dentistry and 4 Biochemistry, Faculty of Dentistry and 5 Faculty
of Medicine, Osaka University, Suita, Osaka 565, JAPAN, 6 Osaka City University Medical School, Osaka 545, JAPAN and ${ }^{7}$ Chester Beatty Laboratories, London SW3 6.JB, UK

\section{[Introduction]}

HCS-2/8 cell line is the first immortal cell line carrying high abilities to synthesize cartilage-type large proteoglycans (PGs) and collagen types $\|$ and $X I$ (12). These characteristics suggest that this cell line is useful for studies on human chondrocyte metabolism. However, the cell line also forms chondrosarcomas in nude mice (1-3). Therefore, to use the HCS-2/8 cell line as a experimental model(s) for studies on human chondrocytes and/or human chondrosarcomas, further characterization of this cell line is indispensable. Here in this report, we describes characteristics of the cell tine in more detail.

\section{[Results and Discussion]}

Characteristic of proteoglycans (PGS) produced by HCS.2/8 cells. HCS $2 / 8$ cells produced proteoglycan (PG) aggregates composed of PG monomers hyaluronic acid and a link protein Using glycerol radient centrifugation and size exclusion chromatography the $P G$ monomers synthesized by the cells were size exclusion chromatography, the PG monomers synthesized by the cells were
identified as cartilage specific, large $P G$ monomers. Northern blot analysis aiso revealed gene expression of aggrecan. The major glycosaminoglycans (GAGs) in the PG monomers was about $38 \mathrm{kDa}$ when determined by Superose $12 \mathrm{FPLC}$ The GAGs were mainly composed of chondroitin-6-sulfate. The PG monomers contained a little keratan sulfate. The cells synthesized a single link protein with a molecular weight of $42 \mathrm{kDa}$. These findings indicate that $\mathrm{HCS}-2 / 8$ celis synthesize $P G$ s of which composition and structure are similar to those in normal cartilage.

Autocrine requlation of expression of the differentiated phenotype of chondrocvtes bv insulin-like growth factors. (IGFs) Both IGF-I and II increased PG synthesis in HCS-2/8 cells in contrast to stimulatory effects of IGFs on rabbit costal chondrocytes, the stimulatory effect of $\mathrm{GFF}-1 /$ on $\mathrm{PG}$ synthesis in HCS-2/8 celis was more potent than that of IGF-I. Binding and crosslinking studies revealed that HCS-2/8 cells had both IGF-I and IGF-II receptors. The celis expressed mRNAs of IGF-I and IGF-II and produced IGF-I and IGF-II proteins. Mannose-6-phosphate, which is known to bind IGF-il receptors, stimulated $P G$ synthesis and potentiated IGF-II-stimulated PG synthesis. Anti-IGF-I receptor antibody inhibited $P G$ synthesis. These findings suggest that IGFs act on HCS$2 / 8$ cells as autocrine differentiation factors and that IGF-II which had been believed to act through IGF-I receptors stimulates $P G$ synthesis via IGF-II receptors.

Requlation of Proliferation and Differentiation by Other Factors. Like normal chondrocytes, $P G$ synthesis in HCS-2/8 cells was stimulated by insulin and transforming-growth factor (TGF) $\beta$ and inhibited by basic FGF (bFGF) and retinoic acid. In addition, TGF $\beta$, bFGF and retinoic acid stimulated the DNA synthesis or proliferation of HCS-2/8 cells. However, there were some subtle differences between responsiveness of $\mathrm{HCS}-2 / 8$ cells to these factors and that of normal rabbit chondrocytes. For instance, the stimulatory effect on DNA synthesis in $\mathrm{HCS}-2 / 8$ cells was observed only in sparse cultures. TGF- $\beta$ timulated DNA synthesis in the cells cultured even in serum-free medium.

In contrast to normal chondrocytes, HCS-2/8 did not respond to parathyroid hormone. EGF or interleukin 1. We will discuss these differences in detail.

Species specific cytokines interferons, especially, interferons $\alpha$ and $\beta$ dramaticaliy inhibited $P G$ and DNA syntheses in HCS-2/8 cells.

Cell Density-Dependent Expression of Differentiation-Related Genes. The $\mathrm{HCS}-2 / 8$ cells expressed many genes related to chondrocyte differentiation such as collagen types $\|, X$ and $X \mid$, vitamin $D_{3}$ receptor, matrix Gla protein (MGP), IGF$I$ and $I I$ and their receptors and alkaline phosphatase (ALPase). Expression of these genes was depend on celi density in culture. During the rapidly growing phase and subconfiuent phase of cultures, HCS-218 cells were in slightly elongated polygonal shape and had very little extracelluiar matrix but already expressed aggrecan and type II collagen genes. As they approached to expressed aggrecan and type 11 collagen genes. As they approached to their $P G$ synthesis reached a maximum In this phase, MGP was strongly their PG synthesis reached a maximum. In this phase, MGP was strongly
expressed. The cells then became multilayered and formed nodules which showed strong metachromasia when stained with toluidine blue. In this phase, the cells expressed vitamin $D_{3}$ receptor (VDR) and type $X$ collagen which have shown to be expressed in hypertrophic chondrocytes. The cells also expressed mRNA of IGF-I and II and IGF-type I and II receptors. However, in the absence of ascorbic acid (Vit. C). ALPase activity which is a marker of calcification was low. When the cells were treated with Vit. $C$ for more than one week. mRNA level and enzyme activity of ALPase markedly increased. These findings suggest that enzyme activity of ALPase markedly increased. These findings suggest that correspond to proliterating, differentiating, maturing and hypertrophic chondrocytes, respectively, and that ascorbic acid is essential for further differentiation along the process of endochondral ossification.

Proto-oncogene Expression. As described above, HCS-2/8 is a stable human chondrosarcoma cell line with many chondrocytic characteristics. However, the cells also has the capacity to form chondrosarcomas in nude mice. Therefore, we also examined transcript levels of 21 proto-oncogenes by Northern analysis. Using $10 \mu \mathrm{g}$ total RNA, we found no detectable transcripts of 9 protooncogenes (c-sis, c-met, c-src, c-lyn, c-fgr, c-ros, c-pim. Blym and N-myc). but detected transcripts of 12 other proto-oncogenes (int-2, erbB, c-abl, c-raf-1, c-fyn, $\mathrm{K}$-ras, $\mathrm{H}$-ras, c-mos, c-myc, c-myb, c-fos, and c-jum). In the over-confluent phase the levels of c-fos and c-raf-1 which were reported to be expressed in hypertrophic chondrocytes were increased some dozens and about 5 times, respectively, while the level of $\mathrm{c}-\mathrm{ab} / \mathrm{was}$ about $1 / 5$ th of that in the sparse subconfluent and confluent phases of culture. The level of int-2, a FGF-related proto-oncogene, increased about 10 -fold in the confluent and overconfluent phases of in vitro culture. We will discuss physiological and pathologica significances of the changes in expression of these proto-oncogenes.

In conclusion, the HCS-2/8 line had many characteristics very similar to those of normal chondrocytes, indicating that the cell line should be usefui for studies on human chondrocytes. On the other hand, the cell line had also some characters different from those of normal chondrocytes. Further studies on these differences should be helpful in understanding the tumorigenicity of human chondrosarcomas.

\section{[References]}

1. Takigawa M Taima K Pan, $\mathrm{H}-\mathrm{O}$ Enomoto M Kinoshita, A F Suzuki Takano, $Y, \&$ Mori, $Y$. (1989) Cancer Res. 49, 3996-4002.

2. Enomoto, M. \& Takigawa, M (1992) In Biological Regulation of The Chondrocyte (M. Adolphe Ed.) pp. 321-338. CRC Press., Boca Raton, FL

3. Takigawa, M., Pan, H-O., Kinoshita, A., Tajima, K., \& Takano, Y. (1991) Int. J. Cancer, 48, 717-725

4. Takigawa, M., Pan, H-O., Enomoto, M., Kinoshita, K., Nishica, Y., Suzuki, F., \& Tajima, K. (1990) Anticancer Res., 10, 311-316.

5. Zhu, J.-D., Pan, H-O., Suzuki, F. \& Takigawa, M. (1994) Jpn. J. Cancer Res, $85,364-371$

Table 1. Cell density-dependent expression of differentiation-related genes and proto-oncogenes by HCS-2/8 cells

\begin{tabular}{lccll}
\hline Phase in culture & growing & subconf. & confluent & overonfluent \\
\hline Aggrecan mRNA & + & +++ & ++ & + \\
$\alpha 1(I I)$ mRNA & ++ & ++ & + & + \\
$\alpha 2(X \mid)$ mRNA & $D$ & + & ++ & ++ \\
$\alpha 1(X)$ mRNA & NO & ND & ND & + \\
MGP mRNA & + & ++ & +++ & NO \\
VDR mRNA & + & + & + & +++ \\
ALPase mRNA & ND & ND & + & $+(+$ vit. C; up) \\
IGF-I \& II mRNA & + & + & + & +++ \\
IGF.| \& II R mRNA & ND & ND & ND & + \\
int-2mRNA & + & + & ++++ & ++++ \\
C-fos mRNA & + & + & + & +++ \\
C-ab/mRNA & +++ & +++ & ++ & ++ \\
C-rat- 1 mRNA & + & ++ & ++ & +++ \\
\hline Stage in & prolif- & differen- & maturation & hypertrophy \\
differentiation & eration & tiation & & \\
\hline
\end{tabular}

ND: not determined.

\section{P1-2}

MOLECULAR CLONING AND FUNCTIONAL EXPRESSION OF HUMAN CHONDROMODULIN-I(hCHM-I) AND SEQUENCE ANALYSIS OF AN UPSTREAM REGION OF hCHM-I GENE

Kazuhiro Takahashi, Junko Suzuki, Takaharu Kohno, Akiko Mori, Jun Kondo, Yuji Hiraki* and Fujio Suzuki*. Research Center, Mitsubishi Kasei Corporation, Kanagawa 227, JAPAN. *Department of Biochemistry, Faculty of Dentistry, Osaka University, Osaka 565 , JAPAN

Growth and maturation of epiphyseal growth-plate cartilage play an important role in endochondral bone formation. Previously we reported purification of growth promoting activity from an extract of felal bovine epiphyseal cartilage, which we named Chondromodulin-I (ChM-I) (1). Subsequent cloning of bovine ChM-I (bChM-I) cDNA revealed bChM-I consist of 121 amino acids with three possible glycosylation sites and is coded as the C-terminal part of a larger precursor. On northern blot analysis, ChM-I mRNA was specifically expressed in cartilage. Recently we succeeded in the molecular cloning of human ChM-I (hChM-I) cDNA. From its nucleotide sequence, primary structure of hChM-I was deduced, and compared with its bovine counterpart.

[Methods] Screening of human genomic Library: A lambda EMBL3 genomic library of human placenta was obtained from Clontech (Palo Alto). The library was screened by hybridization with a probe labeled by a random labeling method (2). The EcoRIEcoRI fragment derived from the bovine ChM-I cDNA clone (1) was used as prove. Hybridization-positive phage clone was isolated by repeated plaque purification.

Nucleotide Sequencing : Appropriate DNA fragments were subcloned into pBluescript SK(-) and sequenced by the chain termination method (3) modified for Dupont Automatic nuclcotide sequencer.

RNA purification and RT-PCR: Total RNA was extracted from 
human chondrosarcoma tissues by the guanidine-thiocyanate method (4). The chondrosarcoma cDNA was synthesized by Reverse transcriptase with the annealed anchor primers consisted of primer 1 (5'CTCGAGGCCATGGCGGCCGCTTTTTTTTTTTTTTTTTTTTTTTTTTT' TTTTTTTTTTT-3') and primer 2 (5-GCGGCCGCCATGGCCTCGAG-3), using total RNA extracted from chondrosarcoma as a template. PCR reaction was carried out by the following procedure. The primer 3 (5'AGTCTCCAAGTGCCTCACT-3), which was synthesized as an upstream region primer on the basis of human genomic sequence. and the primer 4 (5-CGAGGCCATGGCGGCC-3') corresponding to a part of the primer 2 were annealed with chodrosarcoma cDNA. Amplification by $\mathrm{PCR}$ was performed 35 cycles as described previously (5), using a Geneamp Kit (Perkin-Elmer-Cetus). The nested PCR followed by using the primer 5 (5-CATGACAGA GAACTCCCA-3') near the initiation-codon ATG and the primer 6 (5 ACACCATGCCCAGGATGC-3) which was synthesized on the basis of the nucleotide sequence surrounding the stop-codon in bChM-I CDNA.

3-RACE (Rapid Amplification of CDNA End method) : After nucleotide sequencing of the entire coling region of hChM-I PCR clones described above, a pair of primer was designed for 3-RACE (6): primer 7 (5'CCCTAGACTGGATCAC-3') and primer 8 (5) CGAGGCCATGGCGGCC-3'). Thirty-five cycles of PCR yielded a DNA fragment of 3 untranslated sequence.

[Result and Discussion] Our previous study indicates that bChM-1 is coded as a C-terminal region (121 amino acids) of a larger precursor. The precursor protein consists of 335 amino acids, and has a hydrophobic transmembrane domain at near N-terminal part which is rich in varine, leucine and isoleucine. Thus ChM-I precursor is assumed to be expressed as a transmembrane protein. Mature ChM-I protein occurs by proteolytic digestion at the potential processing signal (KEIQRERR underlined in Fig. 1) which precedes the mature bChM-I sequence. This signal sequence is homologous to a processing signal of human complement C5

precursor and can be recognized by a cextain endoprotease (7). Three possible glycosylation sites were identified at $\mathrm{T}^{9}, \mathrm{~T}^{22}$ and $\mathrm{N}^{29}$ in bChM-I. N-terminal two third of bChM-I precursor is assumed to reside on cell membrane. We termed this portion of the precursor as chondrosurfactant protein (Ch-SP) (1), whose biological function remains unknown.

\footnotetext{
Fig. 1 Comparison of Amino Acid Sequences

The upper and lower sequences represent primary amino acid sequences of bChM-I and hChM-I precursors, respectively. Computer analysis was done by GENETYX-MAC (Software Deyelopment Co., Ltd. Tokyo Japan). Pracessing signal sequences are underlined.

1' MTENSDKVPIALVGDDVEFCSPPAYAAVTVRSSPARLI_KVGNVLISGAVLLLLGAIG $* * * * * * * * * * * * * * * * * * * * * * * * * * * * \ldots * * * * * * * * * * * * * * * * * * * * * * * * * * . * * * *$

1" MTENSDKVPIALVGPDVEFCSPPAYATLTVRSSPARLLKVGANVISGAVLLLFGIG

61' AFYFWKGSDNHTYNYHYTMSINGKLDOGSMEIDAGNNLETFMMGSGAEEAVEVNDFQNGI $* * * * * * * * * * * * * * * * * * * * * * * * * * * * * * * * * * * * * * * * * * * * * * * * * * * \ldots . . * * * * * * * *$

61" AFYFWKGSDSHI YNVHYTMSINGKLQDGSME IDAGMLLTFKMGSGAEEAIAVNDFQNGI

121' TGIRFAGGEKCY KAQVKARIPEVGTMTKQSISSELEGKIMPVKYEENSLIWVAGDQPVK **************************..********.*************************

121" TGIRFACGEKCY IKAOUKARTIEVGAVTKOSISSKLEGK IMPVKYEENSUIWVAVOQPVR

181' DNSFISSEVLELCGDLPIFWL KPTYPYE IQRERRELVRK IVTTTTTRRLRSGPGGTPAPG

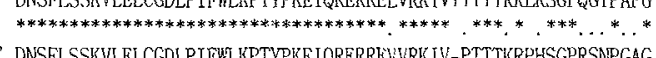

181" DNSFLSSKVLELCGDLPITULXPTYPREIQRERREWRKIV-PTTTKRPHSGPRSNPGAG

241' RPNNGTRPSVQEDAEPFNPDNPYHQQEGESMTFIDPRLDHECICCIECRRSYTHCQKICEP 240" RLNNETRPSVQEDSQAFNPDNPYHOQEGESMTFDPRLDHEGTCCIECRRSYTHCQKICEP

301' LGGYHPWPYNYQGCRSACRVIMPCSWWWARILGMV

$* * * * * * * * * * * * * * * * * * * * * * * * * * * * * * * * * * * * *$

300" LGGYYPWPYNYQGCRSACRVIMPCSWWARILGMY
}

PCR amplification yielded three independent clones corresponding to a coding region of hChM-I CDNA. Figure 1 shows the amino acid sequence of major type cDNA clone, hChM-I 3-6. The amino acid sequence of hChM-I precursor was $92 \%$ identical to that of bChM-I precursor.

Unexpectedly, however, sequence homology between mature hChM-I and its bovine counterpart was only $86 \%$ which was lower than that of the entire precursor (Fig. 1). Most amino acid substitutions (16 amino acid residues) in mature ChM-I were found in the $\mathrm{N}$-terminal domain of the molecule which contains all three glycosylation sites. One amino acid deletion was also identified in this domain of the molecule. Bovine ChM-I has a cluster of ThI residue $\left(T^{n}\right.$ to $\left.T^{12}\right)$ in the $N$-terminal domain. One of the residue $\left(T^{9}\right)$ was glycosylated. In human ChM-I, this cluster was replased by PTTT due to a substitution and deletion of one $T$ residue. Moreover, a sequence (QGTPAP) surrounding the other O-glycosylation site $\left(\mathrm{T}^{22}\right)$ in bChM-I was replased by RSNPGA. N-Glycosylation motif (NGT) in bChM-I changed into NET which is still valid as an $\mathrm{N}$ glycosylation motif. In contrast, C-terminal half of the mature ChMI molecule, which contains all eight cysteine residucs, was completely conserved except for one amino acid residue. Previous chemical analysis of bChM-I indicated that these cight cysteine residues are linked by disulfide-bonding. Taken together, this domain of the molecule probably fulfills structural requirements for expression of its biological activities.

On the other hand, the present sequence comparison revealed a remarkable conservation $(96 \%$ identity) of a sequence corresponding to Ch-SP. This high degree of sequence conservation implies functional importance of this putative transmembrane protein, Ch-SP, which remains to be clarified.

[Acknowledgements] We thank Dr. Y. Kotoura (Kyoto Univ. Medical School) for providing us with human condrosarcoma tissues, This work was supported in parts by the Foundation for Growth Science and The Mitsubishi Foundation.

[References]

1. Hiraki, Y., et al. (1991) Biochem. Biophys. Res. Commun. 175,971977.

2. Feinberg, A. P., and Vogelstein, B. (1983) Anal. Biochem. 132,6 13 .

3. Sanger, F., Nicklen, S., and Coulson, A. R. (1977) Proc. Natl, Acad. Sci. U.S. A. $74,5463-5467$.

4. Chirgwin, J. M., et al. (1979) Biochemistry 18,5294-5299.

5. Okada, H., et al. (1989) Biochem. Biophys. Res. Commun. 162 , $1553-1559$.

6. Frohman, M. A., et al. (1988) Proc. Natl. Acad. Sci. U.S. A. 8 5, $8998-9002$.

7. Hosaka, M., et al. (1991) J.Biol. Chem. $266,12127-12130$.

8. Howgood, S. and Clements, J. A. (1990) J.Clin. Inve. 8 6, 1-6. 


\section{$18 \mathrm{P} 1-3$}

RESISTANCE OF HUMAN OSTEOARTHRITIC CHONDROCYTES TO GROWTH HORMONE AND INSULIN-LIKE GROWTH FACTOR-1.

Johanne Martel-Pelletier, Sylvain Doré, Jean-Pierre Pelletier. Louis-Charles Simard Research Center, Notre-Dame Hospital, University of Montreal, Montreal H2L 4K8 CANADA.

In degenerative joint diseases, such as osteoarthritis $(\mathrm{OA})$, the balance between the synthesis and degradation of matrix macromolecules is disturbed and in the evolved stage of the disease the degradative process exceeds the reparative one, leading to a total loss of cartilage and eburnation of bone. It is, therefore, of interest to understand the influence of growth factors on this equilibrium. Several growth factors are known to modulate cartilage homeostasis. The growth hormone (GH) and the insulin-like growth factor (IGF-1) appear to be the most important growth factors affecting the anabolism of the major molecules found in cartilage.

We investigated the anabolic role of GH and IGF-1 in normal and OA human adult cartilage. Since the action of these growth factors is mediated through membrane receptors we first looked at their expression and presence, and investigated their biological response in human normal and $O A$ chondrocytes.

[Methods] Articular cartilage specimens were obtained either from patients undergoing knee replacement or from normal individuals. Chondrocytes were released from the cartilage by sequential enzymatic digestion, and seeded at high density. All the binding experiments were performed on primary cell culture in which, unless otherwise mentioned, fetal calf serum was removed 24 hours prior to the experiment. For the binding assay, cells were incubated with increasing concentrations of labeled rhGH or thIGF-1 in PBS, $\mathrm{pH} 8.0$ containing $1 \%$ BSA for 4 hours at $22^{\circ} \mathrm{C}$ with or without 100 -fold excess of radioinert $\mathrm{GH}$ or IGF-1. Competition experiments for IGF-I were carried out by incubating chondrocyte with ${ }^{125} \mathrm{I}-\mathrm{IGF}-1$ in the presence or absence of increasing concentrations of rhIGF-1 rhIGF-II and rhInsulin. Affinity cross-linking experiments were performed with the crosslinker disuccinimidyl suberate after an incubation of chondrocytes with ${ }^{125}$ I-IGF-1 in the presence or absence of IGF-1. Furthermore, the chondrocytes were subjected to SDS-PAGL electrophoresis and autoradiography. The IGF receptor type was investigated by incubating chondrocytes with a specific monoclonal antibody against human type I IGF receptor $(\alpha I R 3)$ in prior to the receptor binding assays.

Total RNA was extracted from freshly released chondrocytes and mRNA used for Northern blot or PCR analysis.

GH biological response was monitored by the IGF-1 determination. Total IGF-1 was cxtracted and levels determined by a radioimmunoassay. IGF-1 biological activity was determined using incorporation of radioactive proline after IGF-1 stimulation.

[Results] In order to investigate the putative action of $\mathrm{GH}$ on human adult cartilage, we first examined the expression and presence of $\mathrm{GH}$ receptor in normal and $\mathrm{OA}$ chondrocytes. Results showed that human adult chondrocytes possess the GH receptor mRNA. However, binding assays with ${ }^{125} \mathrm{I}$-GH failed to demonstrate specific binding in either normal or $\mathrm{OA}$ chondrocytes.

Incubation of chondrocytes with rhGH $(0-100 \mathrm{ng} / \mathrm{ml})$ over a period of 8 days failed to show an increased IGF-1 secretion of both chondrocyte types. However, these articular chondrocytes showed their ability to secrete de novo IGF-1. Importantly, the IGF-1 basal secretion was significantly ( $\mathrm{p}<0.005$ ) enhanced in $\mathrm{OA}$ cells than in normal ones on any given day.

IGF-1 binding experiments in normal and $\mathrm{OA}$ chondrocytes demonstrate that non specific binding is less than $5 \%$. Specific binding is dose-responsive and saturable for both cell types. Scatchard curve yielded linear plots indicating a single binding site. Binding experiments revealed that the receptor affinity (Kd) for normal chondrocytes is $1.4 \pm 0.4 \mathrm{nM}$ with $26.8 \pm 5.5 \times 10^{3}$ binding sites/cell. OA chondrocytes showed a lower affinity with a $\mathrm{Kd}$ of $15.4 \pm 4.7 \mathrm{nM}$ and a higher receptor density, $1,178.3 \pm 299.5 \times 10^{3}$ sites/cell. Biologica responses with radiolabeled proline after IGF-1 stimulation revealed a non responsiveness by OA chondrocytes, which contrasts with the 2.5 fold enhancement activity in normal chondrocytes.

The type I IGF receptor characterization of normal human chondrocytes revealed that both IGF-1 and IGF-II displaced radiolabeled IGF-1 in a comparable manner; however, insulin at high concentrations weakly displaced IGF-1. Moreover, the anti-type I IGF receptor antibody effectively blocked $(77 \%)$ specific binding in normal chondrocytes. Northern blot analysis with an antisense mRNA probe specific for type I IGF receptor, detected the signal at $11 \mathrm{~Kb}$. Covalent cross-linking analysis on a $6 \%$ polyacrylamide gel revealed two bands, one of $130 \mathrm{kDa}$ and another of approximately $300 \mathrm{kDa}$, characteristic of the type I receptor. Using a gel of $13 \%$, bands were revealed and reflected the presence of the binding protein (IGFBP). Comparison between normal and OA chondrocytes showed an increased intensity in bands corresponding to the IGFBP-3, on the cells as well as in the culture medium.
[Conclusion] This study showed the expression of GH and IGF-1 receptor mRNA in human adult normal and $\mathrm{OA}$ chondrocytes. However, no relationship between $\mathrm{GH}$ stimulation and IGF-I production could be observed, suggesting that GH receptor is not present or is inactive in these adult cells. The higher IGF-1 production of OA chondrocytes than normal, could indicate that factors other than GH modulate IGF-1 production in this diseased tissue. Interestingly, human $O A$ chondrocytes in contrast to normal ones are unresponsive to the IGF-1 treatment despite an increase in IGF-1 binding on these diseased cells. Our results suggest that the increase of IGF 1 binding may involve an enhancement of IGFBP in the OA articular cartilage. By binding IGF-1, the IGFBP will diminish its bioavailability and consequently prevent its anabolic action.

Thus, in spite of a higher secretion of IGF-1 in OA chondrocytes compared to normal ones, the unresponsiveness of OA cells to IGF- 1 might explain, at least in part, the progression of this degenerative disease. 


\section{P2-1}

HUMAN SYNOVIAL FIBROBLAST COEXPRESS INTERLEUKIN-1 RECEPTOR TYPE Y AND TYPE II: THE ENHANCED BINDING TO INTERLEUKIN-I IN OSTEOARTHRITIC CELLS IS RELATED TO AN INCREASED LEVEL OF TYPE I RECEPTOR.

Jean-Pierre-Pelletier, MBark Sadouk, François Mineau, Kayghobad Kiansa, Ginette Tardif, Johanne Martel-Pelletier. Louis-Charles Sinard Research Center, Notre-Dame Hospital, University of Montreal, Montreal H2L 4K8, CANADA.

Osteoarthritis (OA) is a common rheumatic disorder characterized mainly by a progressive erosion of articular cartilage which is believed to be related to the proteolytic degradation of extracellular matrix. Previous studies have shown the presence of an increased level of latent and active metalloproteases (MMP) in OA cartilage (1). Proinflammatory cytokines such as interleukin-1 (IL-1) and tumor necrosis factor (TNF- $\alpha$ ) are believed to mediate the catabolism in OA tissue (2). IL-1 has been detected in $\mathrm{OA}$ synovial tissue (1) and has been shown to induce, in vitro, the synthesis of MMP by synovial cells and chondrocytes.

The action of IL-1 is mediated by the binding of the cytokine to specific membrane receptors. Two distinct $\mathrm{IL}-1$ receptors have been identified and cloned. IL-1-RtI ( $80 \mathrm{kDa}$ ) is preferentially expressed on T lymphocytes while IL-1-RtII (68 $\mathrm{kDa}$ ) is expressed on $B$ lymphocytes. The role of IL-1 in OA and rheumatoid arthritis is widely documented (3), but little data is avatlable for $I L-1-R$ in these arthropathies. A recent study from our laboratory has demonstrated that an increased level of IL-1-RtI in OA chondrocytes could play a role in the pathophysiology of this disease (4)

ln the present study, we have investigated the number and the level of expression of IL-1-R in normal human and OA synovial fibroblasts, as well as examined the type of receptor which mediates the biological response of these cells.

[Methods] Synovial tissue specimens were obtained from OA patients undergoing total knee joint replacement and normal controls at autopsy. Specimens were dissected and cells were released by sequential enzymatic digestion (5) with $1 \mathrm{mg} / \mathrm{ml}$ pronase for one hour followed by six hours with $2 \mathrm{mg} / \mathrm{ml}$ collagenase at $37^{\circ} \mathrm{C}$ in DMEM supplemented with $10 \%$ heat inactivated FCS and antibiotics. Synoviocytes were then seeded at high density and allowed to grow for five days in DMEM containing $10 \%$ FCS and antibiotics before the binding assay. Twenty four hours prior to the assay, the medium was removed and the cells incubated in serum-free medium.

Direct binding experiments were performed under saturating conditions (4). Monolayer cultures of synoviocytes were washed in PBS and incubated in the binding buffer (PBS,

$10 \mathrm{mM}$ HEPES, $0.5 \%$ gelatin, $\mathrm{pH} 7.4$ ) with ${ }^{125} \mathrm{I}-\mathrm{IL}-1 \mathrm{~B}$ (up to $250 \mathrm{pM}$ ) with or without 100-fold molar excess of uniabeled thlL-1B. The data were analyzed by the LIGAND computex program.

Binding experiments were also done in the absence or presence of anti-IL/-RtI or antiIL-1RtII antibodies: $(0-40 \mu \mathrm{g} / \mathrm{ml})$. Non immune rat IgG was used as a control.

For polymerase chain reaction (PCR), $2 \mu \mathrm{g}$ of total RNA from confluent cultures of primary $O A$ and normal synoviocytes was converted to single-stranded cDNA with $45 \mathrm{U}$ of M-MLV reverse transcriptase. Amplification of CDNA was carried out using specific oligonucleotide priners: IL1-REI or IL1-RtII.

For slot blot analysis, the total RNA was isolated from contluent cultures of primary $O A$ and normal synoviocytes, and the experiment performed on a nylon membrane. The membrines were hybridized ${ }^{32} \mathrm{P}$-labeled ILl-Rtl riboprobe. GAPDH probe was also used as a control of the RNA guantity loaded onto the slots.

Biological activity was measured on synoviocytes after being incubated with increasing concentrations of anti-IL-1RtI, or anti-IL-IRtII, or non immune isotype antibody I hr prior addition of rhll-1B $(200 \mathrm{pg} / \mathrm{ml})$. Cells were incubated at $37^{\circ} \mathrm{C}$ for $24 \mathrm{~h}$. Supernatants were harvested and tested for $\mathrm{PGE}_{2}$ by a radioimmunoassay.

The statistical analysis were done using Student's 2-tailed t-test. P values less than 0.05 were considered significant.

[Results] The binding data revealed the presence of a single class of high affinity IL $1-R$ with no difference in the receptor affinity between $O A$ and normal cells. The number of receptors per cell was, however, significantly higher $(p<0.004)$ in OA synoviocytes than in normal controls; $2534 \pm 187$ versus $1310 \pm 96$. This increase in the level of $\mathrm{IL}-1 \mathrm{R}$ was transient since the binding level was similar to normal controls after the $O A$ cells were transfered into a second passage. PCR data revealed that the ILI-RtI and ILI-RtII are coexpressed in both OA and normal synoviocytes, although the level of IL-1RII mRNA was much more predominantly expressed in all samples. However. no difference in the level of ILI-RII mRNA was nbserved between $O A$ and normal synoviocytes, as determined by slot blot analysis. A blocking antibody against the ILl-RtI completely inhibits, in $O A$ and normal synoviocytes, the receptor binding and the $\mathrm{PGE}_{2}$ production stimulated with $\mathbb{L}-1 \boldsymbol{B}$. Treatment with the anti-IL-RUII was ineffective.

[Conclusion] These findings indicate that the IL-1-RtI is upregulated in OA synoviocytes and is responsible for mediating the biological activation of these cells by IL-1. This phenomena is probably secondary to an abnormality in the post-transcriptional regulation of IL1-RtI gene.
Although the IL-RtII gene is (weakly) expressed in these cells, this receptor type does not seem to be responsible for any significant binding of the natural ligand or to be responsible for IL-1 biological effect.

[References]

1. Dean, D.D. (1991) Semin. Arthritis Rheum. 20 (Suppl 2), 2-11.

2. Pelletier, J.P., DiBattista, J.A., Roughley, P., McCollun, R. \& MarreJ-Pelletier, J. (1993) Osteoarthritis, Edition of Rheunatic Disease Clinics of Nont America (R.W. Moskowitz, Ed.) W.B. Saunclers Company Publishers, Philadelphita, pp 545-568.

3. Arend, W.P. \& Dayer, J.M. (1990) Arthritis Rheum, 33, 305-315.

4. Martei-Pelletier, J., McCollum, R., DiBattista, J.A., Faure, M.P., Chin, J.A., Fournier, S., et al. (1992) Arthritis Rheum. 35, 530-40.

5. Martel-Pelletier, J., McCollum, R., Pelletier, J.P. (1993) Biochim. Biophys. Acta. 1175, 302-305.

\section{P2-2}

\section{Nitric Oxide and Chondrocytes}

Martin Lotz, University of California, San Diego

Osteoarthritis (OA) is the most common musculoskeletal disorder and most cases of $O A$ develop as a function of increasing age. Age-related changes in articular cartilage include altered composition of extracellular matrix and, as a result, impaired mechanical properties. Cartilage of older individuals also shows a profound reduction in thickness and cellulanty.

Our hypothesis suggests that, as a function of aging, cartilage cellularity decreases, cartilage repair mechanisms decompensate and this leads to the development of $\mathrm{OA}$. Based on this concept we examine stimulators and inhibitors of chondrocyte proliferation and changes which develop duing aging or human anticular cartiage.

A growth factor xesponse profile was established for primary human articular chondrocyles. The three isoloms of TGFis were the most potent stimuli. IGF, PDGF and bFGF also function as chondrocyte growth factors but are much weaker than TGFI3. IL-1 inhibits chondrocyte proliferation induced by serum or TGFB and this sepresents the most important difference to fibroblasts where IL-1 stimulates proliferation.

Human articulat chondrocytes are the major intraarticular cell type capable of inducible nitic oxide (NO) synthesis. NO synthesis and expression of mRNA for the inducible nitric oxide synthase (iNOS) are stimulated by IL-1. TNF or LPS but not by chondrocyte growth factors such as TGFB or IGF-1. NO inhibits chondrocyle proliferation when adruinistered from exgenous sources such as sodinm ritroprusside or when nduced by IL-1. The antiproliferative effects of IL-1 on chondrocytes are blocked by NOS inhibitors. NO activates prostaglandin production in chondrocytes and this is a downstream event in the antiproliferative effects of IL- 1 and NO. In constant to chondrocytes, fibroblasts do not produce detectable levels of NO in response 10 IL- 1 and this difference may be one explanation for the differential growth regulatory effects of IL-1 in these two mesenchymal cell yypes. In addition to the inhibition of chondrocyte prolifcration NO also induces DNA fragmentation and altrastructural changes characteristic of apoptosis.

Based on these observation we suggest that the production of NO is one factor which contributes to the rapid age-related decline in chondrocyte proliferative potential and cartilage cellularity. This impairs the ability of cartilage to repair tissue injury which ultimately leads to the development of osteoarthritis. 


\section{Endochondral Bone Formation and Mineralization 17A-1}

BIFUNCTIONAL ROLE OF CHONDROMODULIN-I (ChM-I) IN ENDOCHONDRAL BONE FORMATION

Yuii Hiraki, Tatsuya Koike, Hiroyuki Inoue, Jun Kondo*, Chisa Shukunami and Fujio Suzuki

Department of Biochemistry, Osaka University Faculty of Dentistry, Osaka 565, JAPAN, *Research Center, Mitsubishi Kasei Corporation, Kanagawa 227, JAPAN

Endochondral bone formation is initiated by formation of cartilaginous rudiment in which chondrocytes rapidly grow to become matrix-producing mature cells. It has been noted that a certain component(s) cartilage-matrix acts as an autocrine growth-regulator which mediates cell-matrix interactions in cartilage. Cartilage is one of the main sources of basic fibroblast growth factor (bFGF). It is known as a unique but potent autocrine factor which stimulates anchorageindependent growth, i.e. colony formation in soft agar (1). Tissue extract of cartilage, however, contains chondrocyte-colony stimulating activity which is distinct from bFGF. On the other hand, bFGF is also known as a potent angiogenesis inducer. In spite of abundant presence of bFGF, cartilage is maintained avascular until it calcifies. This phenomenon has been explained by a putative angiogenesis inhibitor in cartilage. In fact, cartilage-extract inhibited DNA synthesis and growth of vascular endothelial cells $(2)$.

Previously we reported a cartilage-specific glycoprotein, i.e chondromodulin-I (ChM-l), which synergistically stimulated DNA synthesis of chondrocytes in the presence of bFGF (3). We report here that ChM-I was identified as a potent colony stimulating factor for chondrocytes. Moreover we identified ChM-I as a growth inhibitor for vascular endothelial cells present in cartilage-extract.

[Methods] Colony-formation Assay: Growth-plate chondrocytes were isolated from the ribs of young New Zealand rabbits, as described (4). A $0.5-\mathrm{ml}$ of base layer of $0.72 \%$ agarose (Sigma, Type VII) in Ham's F-12, medium supplemented with $5 \%$ FBS, $2 \times 10^{-7} \mathrm{M}$ hydrocortisone $60 \mu \mathrm{g} / \mathrm{ml}$ transferrin (Medium A) was added to a 12-well plate. Chondrocytes $(5 \times 103)$ were suspended in $0.5-\mathrm{ml}$ of $0.41 \%$ agarose in Medium $A$, and used as an overlay. Growth factors were dissolved in 1-5 $\mu \mathrm{l}$ of Medium $A$ with $0.5 \%$ bovine serum albumin and added only once on the second day after cell seeding. Cultures were maintained for 8-10 days without addition of any growth factors.

DNA Synthesis Assay of Cultured Endothelial Cells: Vascular endothelial cells were isolated from bovine carotid arteries by the

scraping method (5). The cells $\left(4 \times 10^{3}\right.$ cells/well) were inoculated in a 96-multiwell plate, and cultured in $100 \mu \mathrm{l}$ MEM containing 20\% FBS. When culture became subconfluent, the medium was replaced. Sample solution (1-3 $\mu$ l $)$ was then added to the culture. After incubation for 12 $h r$, the cells were labeled with [ $3 \mathrm{H}]$ thymidine $(0.5 \mu \mathrm{Ci} /$ weli $)$ for another $4 \mathrm{hr}$. Radioactivity incorporated into DNA was counted in a scintillation spectrometer.

[Results] Rabbit growth-plate chondrocytes were suspended in purified agarose and plated in a 12 -well plate. Without bFGF, none of cells grew 10 form a colony even after incubation in the presence of $5 \%$ FBS for 8 days, although the cells were viable. Basic FGF $(0.4 \mathrm{ng} / \mathrm{ml})$ markedly stimulated formation of chondrocyte-colonies (Fig. 1). On the other hand, ChM-I $(600 \mathrm{ng} / \mathrm{ml})$ clearly stimulated colony formation of the cells. Its activity was weaker than that of bFGF. However, in the presence of bFGF, ChM-] synergistically stimulated colony formation. On Day 4 , synergistic action was already evident. After incubation for 8 days, $\approx 900$ cells out 5000 formed colonies which were apparently larger than those formed by bFGF alone.

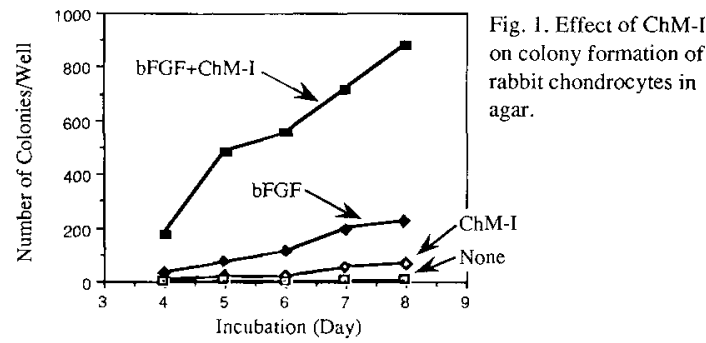

Guanidine-extract from fetal bovine cartilage contains growthinhibitor(s) for cultured vascular endothelial cells (2). We purified the growth-inhibitory activity from the guanidine-extract by monitoring inhibitory activity on DNA synthesis of cultured vascular endothelial cells, and identified ChM-I as an active component in the extract by amino acid sequence analysis. As shown in Fig. 2, purified ChM-I inhibited DNA synthesis of endothelial cells cultured in the presence of $20 \%$ FBS in a dose-dependent manner. The inhibitory effect was detectable at a concentration of $=100 \mathrm{ng} / \mathrm{ml} \quad(=4 \mathrm{nM})$, and became maximal at $\approx 1 \mu \mathrm{g} / \mathrm{ml}(\approx 40 \mathrm{nM})$. The data indicated that ChM-I is one of the potent inhibitor for growth of endothelial cells.

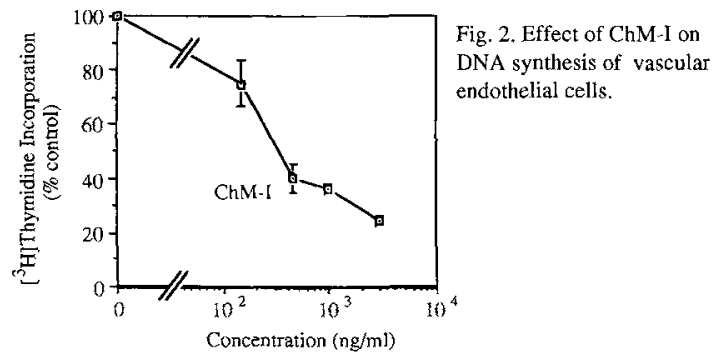

[Discussion] Cartilage is known as an avascular tissue which is exceptional among tissues of mesodermal origin. Chondrocytes exhibit autonomous growth character in vitro which exemplified by feasibility of suspension culture and colony formation in soft agar. Autocrine growth regulation is assumed behind the autonomous growth of chondrocytes. We demonstrated that $\mathrm{ChM}-\mathrm{I}$ was a potent colony stimulating factor for chondrocytes in the presence of bFGF, while it inhibited growth of vascular endorhelial cells. Thus a cartilage-specific growth modulator, ChM-l, acted bifunctional depending on cell-type. Chondromodulin-I plays an important role in morphogenesis of cartilage.

[Acknowledgments] This work was supported in parts by the Mochida Memorial Foundation for Medical and Pharmaceutical Research and the Senri Life Science Foundation.

[References]

1. Kato, Y., Iwamoto, M. \& Koike, T. (1987) J. Cell. Physiol. 133, 491 498

2. Takigawa, M., et al. (1988) J. Bone Min. Metab. 6, 83-92

3. Hiraki, Y., et al. (1991) Biochem. Biophys. Res. Commun. 175, 971 977.

4. Shimomura, Y., Yoneda, T. \& Suzuki, F. (1975) Calcif. Tissue Res. 19, $179-187$.

5. Hagiwara, H., et al. (1984) Thrombosis Res. 33, 363-370. 
17A-2

ROLE OF RETINOIC ACID AND ATP IN TERMINAL DIFFERENTIATION AND MINERALIZATION OF CARTILAGE

Irving M. Shapiro, Masashi Hatori, Cristina Teixiera, Masahiro Iwamoto* and Maurizio Pacifici

School of Dental Medicine, University of Pennsylvania, Philadelphia, PA 19104 USA, * Department of Anatomy and Cell Biology, Osaka University Faculty of Dentistry, Osaka 565 JAPAN.

In the cpiphyseal growth plate, chondrocyte maturation and the subsequent mineralization of the extracellular matrix is accompanied by dramatic alterations in energy metabolism. To explore the relationship between these two events, we used retinoic acid (RA) to promote chondrocyte maturation in culture. Using this system we asked the following questions: (i) does RA treatment of cultured chondrocytes in vitro induce a change in energy status similar to that seen in the hypertrophic region of the maturing growth cartilage in vivo; (ii) do chondrocytes secrete nucleotides; (iii) does the presence of extracellular nucleotides modulate chondrocyte function? [Methods] Maturing chondrocytes were isolated from the cephalic region of Day 18 chick embryo sterna and grown for 7-14 days in monolayer until confluent; the cells were then treated with $10-300 \mathrm{nM}$ RA. Immature chondrocytes from the caudal region of sternum were grown in parallel and served as control cells for the study. At the end of the culture period, cells were harvested using a rapid freezing technique. The energy status of the cells was determined using HPLC; pyruvate kinase and glycolytic enzyme activities were evaluated using biochemical techniques. In addition, we measured the lactate and adenine nucleotide content of the medium. [Results and Discussion] We found that in maturing cephalic cell cultures, RA had a rapid and profound effect on oxidative metabolism. The retinoid caused a reduction

in the energy charge ratio (ECR) and the ATP/ADP ratio, and a sharp decrease in cell ATP levels. Maximum inhibition was observed when the RA concentration was 10-35 nM. Compared with the adenine nucleotides, creatine phosphate levels were decreased to a lesser extent by RA, aithough there was substantial inhibition of creatine kinase activity. We expected to find a compensatory elevation in glycolytic activities; however, the lactate levels in the medium of the treated cells indicated that anaerobic glycolysis was depressed. In contrast to the cephalic chondrocytes, when caudal cell cultures were treated with RA, lactate formation was stimulated and there was minimal effects on oxidative metabolism. The unique energy state of the RAtreated chondrocytes was termed minimal energy state. To determine the mechanism of inhibition of glycolysis, we measured the activity of pyruvate kinase in RA-treated cephalic cells. We found that the activity of this key glycolytic enzyme was profoundly and rapidly inhibited by the retinoid (Figure 1). Since there was a profound decrease in cell adenine nucleotide levels we considered the possibility that adenine nucleotides may be required for events that lead to terminal differentiation. Analysis of nucleotide levels in the culture medium indicated that in parallel with the change in energy status there was an increase in the medium ATP, ADP and AMP values. ATP was rapidly, but incompletely, degraded into ADP and AMP. To test the hypothesis that extracellular nucleotides modulated chondrocyte function, we examined the effect of ATP on three major determinants of chondrocyte function: alkaline phosphatase

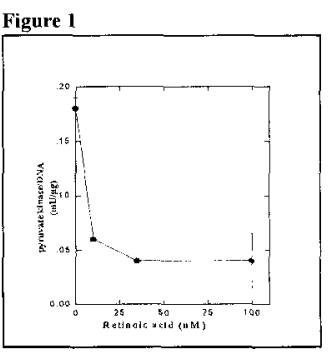
activity, the cell proliferation rate and mineral deposition. For these studies, since ATP is rapidly hydrolyzed in culture, we used concentrations of ATP that were supra-physiological. We found that the nucleotide caused a slight change in cell number. This effect may not be due to ATP itself, since it was mimicked by Pi. We noted that ATP regulated alkaline phosphatase activity as well as serving as a substrate for the enzyme. In addition, we observed that in the presence of ATP, the mineral formed in the culture was a very poorly crystallized apatite. Results of the investigation suggest that RA exerted a profound effect on chondrocye metabolism and that in concert with the metabolic changes, extracellular ATP modulated selected aspects of chondrocyte function and mineral formation and maturation.

\section{$17 \mathrm{~A}-3$}

ROLES OF PARATHYROID HORMONE AND THYROID HORMONE IN TILE CONTROL OF ENDOCHONDRAL BONF. FORMATION

YUKIO KATTO

Department of Biochemistry, Schook of Dentistry, Hiroshima Universily. Hi roshima, 734, JAPAN

Parathyruid hormone (PTH), PIH-related peptide (PTH-rp) and thyroid hormone have various actions on cultured chondrocytes. PTH1-34 and PTH184 stimulated DNA synthesis in fetal chondrocytes. stimulated selectively cartilage-matrix proteoglycan synthesis in retal and postnatal chondrocytes. Furthermore, in growth plate chondrocytes, they suppressed the increases in alkaline phosphatase activity and in type $x$ collagen and lalpha-25-dihydroxyvitamin 03 receptor levels and abolished mineral ization, all of which occurred in paralles untreated cultures in the hypcrtrophic stage. In contrast, the middle and carboxyl-terminal fragments of phatase activity. Furthermore, PrH-receptor levels were up-regulated in the matrix-forming zone of growth plates. The stage-dependent increase in $\mathrm{PTH} / \mathrm{PTH}-\mathrm{rP}$ receptor levels may localize the hormone stimulations of DNA and proteogiycan syntheses and inhibition of precocious hypertrophy in the matrix-forming zone of growth plates. PTH also stimulated the syntheses of matrix metalloproteinases in chondrocyte cultures. The significance of the PTH stimulation of matrix proteinases remains unknown.

In cultures from resting cartilage of ribs, thyroid hormone, concanavalin $A$ and $B M P-2$ acted on the permanent chondrocytes to initiate the terminal differentiation program and to synthesize alkaline phosphatase, whereas PTH1-34 suppressed the enzyme induction even in the presence of concanavalin $A$, the most potent stimulator of chondrocyte hypertrophy. These findings suggest that PTH/PTH-rp is involved in the inhibition of hypertrophy in the permanent cartilaginous region of the rib cartilage.

In this study, the effect of thyroid hormone on proteoglycan degradation was also exanined. In growth plate chondrocyte cultures with $10 \%$ serum, thyroid hormone had a marginal effect on proteoglycan synthesis, alkaline phosphatase activity or syntheses of type II and $X$ collagen in growth plate chondrocyte cultures. Nevertheless, thyroid hormone, at low con centrations, markedy stimulated degradation ar cartilage-matrix proteo glycan. tures treated with thyrold hortherme hever. similar to those in the hor protive endochondral bone formation these findings sugsest that thyroid hor plays a crucial role in the control of proteoglycan metabolisn in growth plates.

Acknowledgment-.-This study was carried out by many menbers of Department of Biochemistry, School of Dentistry. Hiroshima and Osaka UniversiREEERENCES

Suzuki, F., et a1., FiBS Lett., 70, 155-158, 1976

Hato, Y. et al. Endocrinology, 122:1991-1997, 1988

Koike, $\mathrm{T}$, et al, J, Clin. Invest. 85:626-631, 1990

Kato, $Y$ et al. Endocrinology, 127:114-118, 1990

I wanoto, $n$. et al. J, Bíol Chem. 269:17245-17251, 1994 


\section{$17 A-4$}

\section{PARATHYROID HORMONE-RELATED PEPTIDE AND}

\section{ENDOCHONDRAL BONE DEVELOPMENT}

Gino V. Segre, James D. Deeds, and Kaechoong Lee. Endocrine Unit. Massachusetts General Hospital, Department of Medicine, Harvard Medical School, Boston, MA02114, USA.

Parathyroid hormone-related peptide (PTH:P) was originally identified as a causative agent of humoral hypercalcemia of malignancy, a common paraneoplastic syndrome. The $\mathrm{N}$-terminal $1-13$ portion of PTHrP has striking sequence homology with parathyroid homone (PTH), and PTH and PTHrP have been shown to bind to and to activate a common, cloned receptor (1). Whereas PTH functions as a systemic regulator of calcium homeostasis through its action on receptors expressed in bone and kidney, PTHrP has been postulated to function mainly as a paracrine/autocrine regulator of cellular growth and differentiation, through actions mediated at least partly by activation of the common receptor it shares with PTH. This hypothesis is based first on the fact that both PTHrP and its receptor genes are expressed in a wide variety of normal fetal and postnatal tissues. Second, this hypothesis is supported by the observation that either overexpression or null mutation of the PTHrP gene in mice results in abnormal fetal development; targeted overexpression of PTHrP in keratinocytes in transgenic mice results in abnormal hair-follicle development (2), and targeted disruption of the PTHrP gene is lethal and associated with skeletal dysplatia in homozygous mutants (3).

If PTHrP acts as a paracrine/autecrine facior through the activation of common PTH/PTHrP receptors during fetal development, the expression of these two genes must be spatially and temporally correlated. In this study we first examined the localization of transcripts for both PTHrP and $\mathrm{PTH} / \mathrm{PTHrF}$ receprors in endochondral bones during fetal development of rats. Then we analyzed the skeletal abnormalities of "PTHrP-less" mice morphologically and at the molecular level by comparing developing long bones of normal and mutant fetuses.

[Methods] The proliferative status of chondrocyles was analyzed by $\mathrm{H}_{4}$ histone mRNA expression (a marker for cells in the S-phase of the cell (ycle), and their differentiation was analyzed by the expression of transcripts for Types II, and X collagen, PTH/PTHrP receptor, and osteopontin. Apoptosis of chondrocytes also was examined by 3'-end-labeling of DNA fragnents using Biotin-dUTP (TUNEI, assay).

[Results] 1. PTHrP and its receptor mRNA expression during norma endochondral bone develooment. Transcripts for both PTHtP and its receptor were highly expressed in cell-type and stage-specific manners during endochondral bone formation. Since the patterns as well as the sites of expression changed over developmental stages, we first characterized the different stages of endochondral bone formation by examining the expression of chondrocyte/osteoblast differentiation/proifferation "marker" yenes in order to place cells that express PTHrP and its receptor transcripts in the contex $x$ of endochondral bone development. Chondrocytes in developing cartilage were orderly stratified into three layers; (i)early chondrocytes are proliferating, as evidenced by $\mathrm{H} 4$ histone mRNA expression, (ii)hypertrophic chondrocytes, which express Type $X$ collagen mRNA, but do not express $\mathrm{H} 4$ histone mRNA, and (iii)terminal hypertrophic chondrocytes, which express osteopontin mRNA. Maturing chondrocytes reside at the border between layers (ii) and (iii), and express alkaline phosphatase mRNA. At early stages before chondrocyte maturation, PTHrP mRNA was expressed in early chondrocytes, and in focal arteas of the perichondrium, while its receptor mRNA was expressed in early chondrocytes and surrounding mesenchymal cells. At later stages (after chondrocyte maturation), PTHrP was expressed in focal areas of the perichondrium and in hypertrophic chondrocytes, while its receptor mRNA wass most intenscly expressed in non-proliferating, maturing chondrocytes. PTH/PTHrP receptor mRNA expression dramatically decreased in hypertrophic chondrocytes as they enlarged and was not detectable in the mineralized layer, where osteopontin and PTHrP mRNAs were highly expressed. 2.Molecular analysis of abnormal endochondral formation in "PTHrP-less" mice. The orderly stratification of chondrocytes was dramatically altered in the mutant long bones. First, layer (i) was markedly shorened in the mutant throughout the time course studied (from day 15 to day 18). Second, while there was little overlap among cells in layers (i), (ii), and (iii) in normal mice, chondrocytes in mutant long bones were disordered with marked overlap among layers. The loss of orderly stratification in the mutant was more evident in the earlier fetuses. Moreover, whilc few hypertrophic chondrocytes in layers (ii) and (iii) were apoptotic in the normal lony bones, most hypertropkie cells in the mutant long bones were apoptotic from day 15 to day 17.

|Discussion| The close temporal and spatial relationships between gene expression of PTHrP and its receptor during fetal skeletal development are consistent with the hypotheses that PTHrP acts as a paracrine/autocrine peptide factor in endochondral bone development and that a common receptor mediates both the paracrine/autocrine PTHrP signal and the endocrine PTH signal. The changing patterns of the localization of transcripts for these two genes suggest that PTHrP is likely to have roles in the early stages that are distinct and different from its roles in later stages. This is consistent with the most obvious abnormalities in "PTHrP-less" bones, where the proliferating zone of epiphyseal cartilage is markedly shortened, and both mineralization of cartilage and replacement of cartilage by bone appeared to be accelerated (3). Since PTH/PTHrP receptor mRNA expression dramatically decreases in the mineralized layer in nornal cartilage, it is fikely that the activated PTH/PTHrP receptor is involved in retarding cartilage matrix mineralization. If cartilage mineralization occurs prematurely, the bone is shortened and malformed, as occurs in PTHrP-less mutants. These data, when taken together, suggest that PTHrP regulates not only the proliferation and differentiation of chondrocytes, but also cartilage mineralization and its replacement by bone.

[References]

1. Jüppner, H., et al. (1991) Science 254, 1024-1026.

2. Wysolmerski, J. J., et at. (1994) Proc. Natl. Acad. Sci. USA 91,11331137.

3. Karaplis, A., et al. (1994) Genes \& Development 8, 277-289.

\section{Regulatory Mechanism of Expression of Cartilage- Phenotype 17P1-1 \\ ENVIRONMENTAL CONTROL OF CHONDROCYTE DIFFERENTIATION}

Peler Brąckner, Jean Farjanel ${ }^{+}$, and Kathrin Böhme*. Institute of: Physiological Chemistry, Westfälische-Wilhems-Universität, Münster, FRG, +Institut de Biologic et de Chimie des Protéines, Lyon, FRANCE, and *Department of Anatomy and Cell Biology, Harvard Medical School, Boston, USA.

Chondrocyte maturation consists of a cascade of distinct dillerentiation events that is initiated after chondrogenesis and eventually leads to hypertrophic cells. The process extensively occurs in cartilage undergoing endochondral bone formation in development, growth, and repair of long bones or in osteoarthritic joints. In permanent tissues, such as nomal articular cartilage, chondrocyte maturation occurs to a much lesser extent and only in decp zones adjacent to subchondral bone. The stationary cellular environment as well as factors diffusing through the extracellular matrix, such as minerals, nutrients, growth faciors, and hormones are thought to control chondincyte differentiation.

In principle, the role of individual regulators can be investigated in cell culture-experiments, but the interpretation of the results is frequently complicated, if not compromised, by the choice of culture conditions. Undefined components of modia (serum, tissue extracts, etc.) jeopardize the unequivocal assignment of regulatory roles to exogenously added factors.

The regulation of cell differentiation is rendered even more complex by the release of factors by the cclls themselves which may or may not interfere with the action of signals added to the culures. For example, cell viability is subject to a social control in that it depends on the presence of survival signals produced by nearby cells. In the absence of the factors, or if their receptors are not expressed, cells undergo programmed cell death as a default development. As a consequence, studies of cell-regulation must always take into account the concerted action of added rcgulators along with cellular products.

Finally, cellular products controlling differentiation may be dif matrix components. Newly synthesized matrix macromolecules exert their intluence on cellular functions, theil supramolecular organization being importamt. The state of aggregation of newly sectreted matrix macromolectles depends, in turn, on the nature of the stationary enviroument experimentally provided. For example, maintenance of chondiocytes adhering to culture dishes leads to a loss of the cartilage phenotype.

Because of its complexity, the puzzle of environmental factors regulating chondrocyte maturation cannot be solved by a strictly reductionist approach. However, it may be possible to empirically unravel the importance of individual regulators in experimental systems that are defined in the utmost possible manner. For this reason, we have developed a serum-free cul- 
ture system for chondrocytes to eliminate at least the complex, undefined, irreproducible and unnecessary cocktail of signals contained in sera. Employing this system, we have studied the influence of growth faciors or hormones, and the role of the stationary extracellular environment on chondrocyte maturation in culture.

Cells were isolated from chick embryo sterna by collagenase digestion and were cultured in gels of agarose or acid-extracted and fibrillated bovine skin-collagen I. The medium was DMEM, supplemented with $1 \mathrm{mM}$ pyrurate, $1 \mathrm{mM}$ cysteine, and $50 \mu \mathrm{g} / \mathrm{ml}$, each. of $\mathrm{Na}^{+}$. ascorbate and of 2-aminoptopionitrile fumarate. Pepsin digested collagens and alkaline phosphatase activity extracted from the cultures served as molecular markers for different stages of maturation. In addition, the cells were morphologically characterized by light microscopy.

Cells from the cranial third of sterna from 14 to $18 \mathrm{~d}$-old chick embryos in agarose culture maintained the cartilage phenotype (expression of collagens II and XI) and uniformely and spontaneously underwent maturation. The latter process could be accelerated by anabolic signals (IGF-1, insulin, thyroid hormones, or serum). Markers for chondrocyte-hypertrophy (collagen $\mathrm{X}$ and alkaline phiosphatase) were expressed after some time in culture. Addition of caudal cells prevented this development in cranial cells. This could also be effected by media conditionned by caudal cells (in part), or by a mixture of bFGF and TGF- $\beta$ (entirely; 10 $\mathrm{ng} / \mathrm{ml}$, each) [1]. Both factors have been shown to be products secreted by chondrocytes

When cells from the entire sterna were cultured in collagen I-gels under serum-free conditions, the cells dedifferentiated by morphological and biochemical criteria. They became fusiform and produced collagen I after a few days in culture. This development was not influenced by any of the above signals, but was prevented by serum. Consistently with earlier reports [2], the cells became hypertrophic chondrocytes under these conditions.

The data demonstrated that, both, diffusible signals and the nature of the experimental environment influenced chondrocyte differentiation. The precise mechanisms of the action of collagen I fibrils on chondrocytes remains to be elucidated.

[1] Böhme, K., Winterhalter, K.H., and Bruckner, P. (1994). Terminal differentiation of chondrocytes in culture is a spontaneous process and is arrested by transforming growth facto: $\beta 2$ and basic fibroblast growth factor in synergy. Submitted for publication.

[2] Gibson, G. J., Kielty, C. M., Garner, C., Schor, S. L., and Grant, M. E. 1983. Identification and partial characterization of three low-molecular-weight collagenous polypeptides synthesized by chondrocytes cultured within collagen gels in the absence and in the presence of fibronectin. Biochem. J. 211:417-426

\section{CHONDROGENIC DIFFERENTIATION OF A MOUSE EC CELL-LINE, ATDCS}

Chisa Shukunami, Chohei Shigeno*, Fujio Suzuki, and Yuji Hiraki. Department of Biochemistry, Osaka University Faculty of Dentistry, Osaka 565, JAPAN. *Calcium Laboratory, Department of Radiology \& Nuclear Medicine, Kyoto University Faculty of Medicine, Kyoto 606, JAPAN.

Chondrogenesis is a key event in skeletal development of animals. During endochondral bone formation, undifferentiated mesenchymal cells condense to form a cartilaginous core, where chondrocytes undergo a series of changes including proliferation, maturation, and terminal differentiation prior to calcification. Actions of hormones and growth factors have been studied by simulation of these cellular events in primary culture of growth-plate chondrocytes in vitro. However, siudy of an early chondrogenesis has been hampered by a lack of a suitable chondrogenic cell-line.

Recentiy, Atsumi established a clonal cell-line, ATDC5, which was derived from mouse embryonal carcinoma AT805 (1). Insulin induces chondrogenesis of the cells at a high incidence, as evidenced by formation of many cartilage-nodules. We report here that, upon stimulation by insulin, ATDC5 cells keep track of a differentiation pathway which is supposed to occur in epiphyseal growth-plate chondrocytes.

It has been known that chondrocytes respond to parathyroid hormone (PTH) through the PTH/PTHrP receptor which is indistinguishable from that expressed in bone $(2,3)$. Although its physiological role in chondrogenesis is not fully understood, differentiation of ATDCS cells in vitro clearly indicates that expression of the receptor gene is closely associated with early chondrogenesis. [Methods] ATDC5 cells were maintained in DMEM/Ham's F12 (1/1) medium supplemented with $5 \%$ FBS, $10 \mu \mathrm{g} / \mathrm{ml}$ human transferrin and $3 \times 10^{-8} \mathrm{M}$ sodium selenite. For induction of chondrogenic differentiation, bovine insulin $(10 \mu \mathrm{g} / \mathrm{ml})$ was added to the above culture medium. Chondrogenesis and calcification were monitored by staining with $0.1 \%$ Alcian blue and $1 \%$ Alizarin red, respectively after fixation of cells with 95\% ethanol. Expression of the marker genes in the cells was analyzed by Northern blot analysis. Quantitative analysis of mRNA levels in the cells were carried out by slot blot analysis of total cellular RNA. Hybridization probes were prepared by the random-primer method. Cell-surface binding of PTH was assessed by the use of $125\left[\right.$-labeled $\left[\mathrm{Nle}^{8}, \mathrm{Nle}^{18}, \mathrm{Tyr}^{34}\right]$ bovine PTH-(1-34) amide as described (3)

[Results] Figure 1 shows growth-curves of ATDC5 cells cultured in the presence or absence of insulin. Without insulin, the cells rapidly proliferated as characterized by a short doubling time $(17 \mathrm{hr})$. The cells exhibited clear contact-inhibition of growth at confluency, while no expression of phenotype genes such as type II collagen and aggrecan genes was detectable. In contrast, insulin induced re-entry of the cells to a growing state with an interval of postconfluent growtharrest for 3 days. This postconfluent growing stage was characterized by a longer cell doubling (48 hr). In association with postconfluent growth of the cells, Alcian blue positive cartilage-nodules appeared and differentiated chondrocytes dominated in the culture plate within 3 weeks postconfluency. Expression of type II collagen, type IX collagen, and aggrecan genes became detectable and progressively increased along with cartilage-nodule formation.

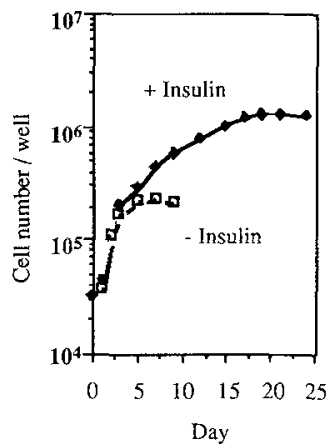

Fig. 1. Growth curves of ATDC 5 cells.

The cells were inoculated at a density of $3.5 \times 10^{4}$ cells/well in a 24 -well plate, and maintained in the presence or absence of insulin $(10 \mu \mathrm{g} / \mathrm{ml})$.

After cessation of growth, expression of these genes reached a maximal level. Then, hypertrophic chondrocytes appeared in close association with dramatic elevation of alkaline phosphatase activity. Expression of type $\mathrm{X}$ collagen gene followed. Alizarin red staining suggested that calcification of cartilage-nodules markedly progressed after 5-7 weeks of culture.

Neither expression of PTH/PTHrP receptor gene nor specific cellsurface binding of PTH was detectable in undifferentiated ATDC5 cells

grown without insulin. Upon chondrogenic differentiation by insulin, expression of PTH/PTHrP receptor gene was dramatically induced in parallel with type II collagen gene expression and slightly precedes aggrecan gene expression (Fig. 2). Appearance of specific binding sites of PTH is also associated with chondrogenic differentiation of the cells.

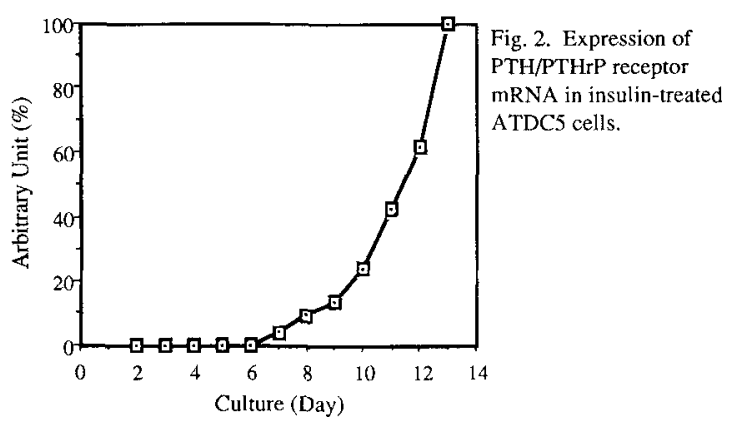

[Discussion] A clonal cell-line, ATDC5, differentiates into chondrocytes at a very high incidence. It offers an reproducible culture system by which we can trace and analyze a course of multiple differentiation stages, from cartilage-nodule formation to calcification, characteristic of epiphyseal growth-plate chondrocytes.

PTH and PTH related peptide (PTHrP) share a common cellsurface receptor for action. PTH stimulates synthesis and maturation of aggrecans synthesized by chondrocytes, though its well-known target organs are kidney and bone (2). Recently ES cells were targered at the PTHrP Jocus. Homozygous mice carrying the mutant PTHrP allele exhibited abnormalities in epiphyseal cartilage which resulted in shortened long bones (4). The present study clearly indicates that acquisition of PTH/PTHrP signaling is closely associated with early chondrogenesis. ATDC5 cells offer a further opportunity for molecular analysis of early chondrogenesis.

[References]

1. Atsumi, T., et al. (1990) Cell Diff. Dev. 30, 109-116.

2. Takano, T., et al. (1985) Endocrinol. 116, 2536-2542.

3. Hiraki, Y., et al. (1991) J. Bone Min. Res. 6, 1373-1385.

4. Karaplis, A.C., et al (1994) Gene Dev. 8, 277-289. 


\section{P1-3}

INDUCTION AND STABILITY OF THE CHONDROCYTE PHENOTYPE IN CELLS IN CULTURE

Arthur Veis, Denise Nebgen, Junehong Chen, Hiroyuki Inoue, Stanley Ciletti and Boris Sabsay. Division of Oral Biology, Northwestern University Dental School, Chicago, Illinois, 60611 , USA

Bone morphogenetic proteins (BMPs) implanted at ectopic sites in vivo act by inducing uncornmitted fibroblast-like cells at the implant site to enter a chondrogenic pathway ultimately leading to the formation of bone. BMPs and other factors can also induce fibroblasts to express the chondrogenic phenotype in vitro. We have demonstrated this chondrogenic induction using one such factor that is derived from the dentin matrix $(1,2,3)$. Fibroblasts induced to become chondrocyte-like by the dentin "chondrogenic agent (CIA)" retain the chondrogenic phenotype for many days in culture (3). On the other hand, bovine articular chondrocytes cultured on tissue culture plastic, spontaneously "dedifferentiate" within a few days and behave morphologically and biochemically as fibroblasts (4). These observations have led to the present study in which we have investigated the nature of bovine CIA (bCIA) and the mechanism of the fibroblast $\Leftrightarrow$ chondrocyte phenotypic transitions induced by CIA or in vitro culture.

[Methods] Bovine CIA was extracted and purified from bovine incisors, molars, and unerupted molars by the procedure of Amar et al. (3) with some modifications. The final reverse phase HPLC purification was carried out on a Vydac $218 \mathrm{TP} 54 \mathrm{C}-18$ analytical column. The chondrogenic activity of each fraction was determined using a modified neonatal rat muscle fibroblast (RMF) ${ }^{35} \mathrm{~S}-\mathrm{SO}_{4}$ incorporation assay (2). The purifed fractions which demonstrated chondrogenic activity were subjected to amino acid analysis, $\mathrm{NH}_{2}$-terminal amino acid sequence analysis and laser desorption (LD) and electrospray (ESD) mass spectrometry for molecular mass determination.

RMF were cultured in the presence of bCIA or bovine BMP (a gift from Dr Marshall Urist). The presence of mRNA for type 1 (COL1) and type II (COL2) collagens was determined as a function of time, by Northem analysis. Similar cultures, in which the culture plates were coated with bCIA by the procedure of Iwata et al. (5), were also examined microscopically after fixation with methanol and staining with toluidine blue. Bovine articular cartilage chondrocytes were isolated from metacarpophalangeal joints from hooves of 18-24 mo. cattle. Slices were carefully taken from the joint surfaces to avoid contamination with synovium. Cells were recovered from the slices following successive pronase and collagenase digestion. The cells were plated in $150 \mathrm{~cm}^{2}$ flasks at a density of $2 \times 10^{5}$ cells $/ \mathrm{cm}^{2}$ in Ham's F- 12 media $+10 \%$ FBS and $0.1 \%$ gentamycin. Culture was terminated at various time periods and the cells were either stained for microscopic examination or the RNA was isolated. Northern and PCR analysis were used to determine the level of various chondrocyte and fibroblast phenotypic mRNAs. The technique of differential display ( 6 ) was used to follow overall changes in gene expression during the culture period.

[Results] Isolation of bCIA. Following $0.6 \mathrm{~N} \mathrm{HCl}$ demineralization a $4 \mathrm{M} \mathrm{Gu} . \mathrm{HCl}$ extract was fractionated on Sephacryl S-100. Fractions activity in the sulfate incorporation assay were combined and subject to reverse phase HPLC. The final chromatography and activity assay, Fig.1, identified peak 5 as the active component. Peak 2 also showed activity significantly above background. Identical chromatography of recombinant hBMP2 and TGF- $\beta$ indicated that TGF- $\beta$ eluted in two peaks, one coincident with peak 2 and the other immediately after peak 5. BMP2 eluted much later than peak 5 . Peak 5 was therefore subjected to amino acid analysis and $\mathrm{NH}_{2}$ - terminal amino acid sequencing. The

\section{antino acid composition was interesting in that there was no detectable Cys. The princjpal $\mathrm{NH}_{2}$ - terminal sequence was:
Leu-Pro-Ala-Gly-Pro-Gly-Leu-Pro-. Mas spectrometry showed that Peak 5 contained molecules of mass 5,805 and 22,315 . Studies of the rat incisor CIA had suggested a $\mathrm{M}_{\mathrm{r}}$ of $6,000-10,000$. Thus, it is likely that the lower molecular mass component is the bCIA Further separation of the two components of Peak 5 , to be followed by activity analysis,
sequencing and mass determination are in} progress.

bCIA induction of the chondrocyte phenotype in RMF. The RNA was collected from RMF plated on plastic (Day 0) and after 6 days of treatment with bCIA. Northern analysis of the mRNA, Fig. 2, showed a down-regulation of COLI mRNA and a marked up-regulation of COL2 mRNA, clearly confirming the ability of $\mathrm{coc} .1$ b bCIA to alter the phenotype of the RMF. The expression of the COL2 mRNA was not detected until day 5 in culnure. RMP cultured in the absence of CIA maintained the fibroblast cultured in the absence of CIA maintained the fibroblast
phenotype. The cells cultured on bCIA aggregated within 10
days to form nodules that stained with toluidine blue, indicating the presence of a proteoglycan rich extracellular matrix. The thodules could be maintained in culture for at least 28 days. could be maintained in culture for at least 28 days.

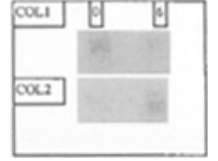
Fig. 2. Northern analysis primary chondrocyte dedifferentiation. For the furst $3-4$ days RMF + CIA. Days $0 \& 6$. primary chondrocytes plated on tissue culture plastic had a rounded appearance, but after 7 days in culture the majority of

at low levels on day zero using Northern blots and PCR, but no COLI was detectable on Westem blots. By day 5, bath mRNA and protein were abundant. Over the same period, COL2 mRNA and expressed protein decreased, however, COL2 mRNA remained at a readily detectable level up to 15 days. A striking change took place in cell actin level as well (Fig. 4). Actin mRNA increase

dramatically as collagen II mRNA decreased. In fact, actin, fibronectin and glyceraldehyde3-phosphate dehydrogenase mRNA

transcription were all up-regulated by Fig. 3. Cultured Chon day 1 in culture. Differential display, comparing days 0 and in culture led to the identification of a number of up and down regulated mRNAs. Three of the sharply up-regulated mRNAs (as cDNAs) were selected for sequencing. One proved to be ribosomal protein S-27. Northern analysis als showed its up-regulation to be time dependent and strongl evident by day 1 in culture. The second was identified as a bovine mitochondrial gene, while the third sequence was not in thegene bank.
[Discussion] As previously reported (3) dentin matrix contains a low molecular weight protein (CIA) which can induce fibroblast-like cells in culture to shift to express secreted proteins phenotypic of chondrocytes. The composition, partial $\mathrm{NH}_{2}$ - terminal sequence and molecular mass data, as well as the chromatographic properties, all indicate that bCIA, priority of the laboratory.

As seen in in vivo studies(7) of bone induction by BMP, the fibroblast $\Rightarrow$ chondrocyte transition must be the result of a series of steps. The data presented above indicate that the appearance of the chondrocyte-specific phenotypic products (e.g. COL2) is a late event. Some clues as to the early steps were provided by examination of the reverse process, the chondrocyte $\Rightarrow$ fibroblast transition. Most significant were the upregulation of actin, fibronectin and GAPDH by day 1 , while production of $\mathrm{COL} 2$ was still high and COL1 was not expressed. Ribosomal protein S-27 was also upregulated prior to COL1 gene expression. These data suggest that changes in cell shape and cytoskeleton, in the mix of ribosomal proteins regulating translation, and in the amounts of enzymes involved in oxidative metabolism must all be established before the "dedifferentiated" chondrocyte can support the synthesis and secretion of products phenotypic of fibroblasts. The inverse series of stages must also apply to the induction of the chondrocyte phenotype in the RMF, and probably accounts for the five day period before COL2 gene expression was detected. The important question then is how the CIA interaction with the RMF cell or chondrocyte interaction with the surface of a plastic culture dish, can so profoundly alter the cell housekeeping protein system? Is there a master gene, such as that proposed for the myoD system $(8,9)$, which determines the cell phenotype? The fact that chondrocytes induced by CIA and cultured in the presence of CIA maintain their chondrogenic phenotype for a long period suggests that this may be the case. Present efforts to examine this hypothesis focus on the very early period of interaction between RMF and CIA.

[Acknowledgments] All of the above work has been supported by grants DE08525 and DE01374 from the National Institute of Dental Research, grant AR13921 from the National Institute of Arthritis, Metabolic and Skin Diseases, and Fellowship support from NIH-NIDR T32 DE07201 and the American Association of Oral and Maxillofacial Surgeons.

[References]

1. Veis, A., Sires, B. \& Clohisy, J. (1989) Connective Tissue Research 23, 137-144.

2. Veis, A., Sires, B., Clohisy, J. Sabsay, B. \& Amar, S. (1990) Biomaterials 11, 16-18.

3. Amar, S., Sires, B., Sabsay, B., Clohisy, J. and Veis, A. (1991) J. Bio]. Chem. 266, 8609-8618.

4. Benya, P.D. \& Brown, P.D. (1986) In Articular Cartilage Biochemistry, (K.E. Kuettner, R. Schleyerbach and V. C. Hascall, Ed.) pp 219-233, Raven Press, New York.

5. Iwata,H. Satomi, O., Sato,K., Sato, T. and Kawamura, M. (1993) Clinical Onthoped. 296, 295-300.

6. Liang, P. and Pardee, A.B. (1992) Science 257, 967-971.

7. Reddi, A.H. In Biochemistry of Collagen, (G.N. Ramachandran \& A.H. Reddi, Eds.) pp 449-478, Plenum Press, New York.

8. Weintraub, H. (1989) Proc. Natl. Acad. Sci. USA. 86, 5434-5438.

9. Choi, J., Costa, M.L., Mermelstein, C.S., Chagas, C., Holtzer,S. \& Holtzer, H. (1990) Proc. Natl. Acad. Sci. USA. 87, 7988-7992. 
17P2-1

MODULATION OF SKELETAL CELL PROLYFERATION AND DIFFERENTIATION BY RETROVIRUSES

P. Günter Strauss, Cornelia Speth, Wolfgang Gimbel, Jörg Schmidt, and Volker Erfle, GSF-Institut für Molekulare Virologie, Neuherberg, GERMANY

A variety of retroviruses closely related to mouse endogenous ecotropic retroviruses have been examined for their effects on the skeleton of mice. In contrast to the osteosarcoma viruses FBR and FBJ, which carry a cellular homologue of the c-fos oncogene, murine leukemia-type retroviruses do not carry a cell derived oncogene homologue and do not cause osteogenic tumors. However, infection of newborn mice with some of the murine leukemiatype retroviruses leads to a massive distortion of the normal bone development $(1,2)$. In vitro, osteogenic differentiation of the chondroprogenitor cells of mandibular condyles can be enforced by infection with osteopathogenic murine leukemia virus-type retroviruses ( 3 ) Together the data suggest that these retroviruses can influence the cell's phenotype by directly or indirectly interfering with the osteogenic differentiation pathway. One possibility is that the activity of the retroviral promoter and the retroviral genes may modulate the expression of cellular genes. The studies on the structure of osteopathogenic murine leukemia virus-type retroviruses and their inteaction with cellular gene expression is expected to improve the understanding of the mechanisms by which regulatory molecules affect the physiology of osteogenic cells and subsequently influence the formation of the skeleton.

\section{Methods}

Newborn mice of the NMRI and CBA/Ca strains were intraperitoneally injected with infectious virus particles from cell free supernatants. Osteoma and osteopetrosis were diagnosed by $\mathrm{X}$-ray analysis and histological examination. The tnolecular cloning of the RFB has been described elsewhere (2). The sequence analysis of the RFB was performed by standard methods.

The basic method of Differential Display PCR has been described previously (4). The method was modified in using an anchor primer sequence related to the loop region of the murine HLH-type gene myoD and primer sequences homologous to the murine Id gene in combination with random primers. RNAs from different time points of tissue cultures and cell cultures were reverse transcribed to cDNA. Differentially expressed RNAs were displayed as PCR products on nondenaturing polyacrylamid gels. Northern-blot and slotblot analysis were performed by standard methods.

Results

The most potent of osteopathogenic murine leukemia virus-type retroviruses, the RFB (Reilly-Firkel-Biskis) virus, was injected into newborn CBA/Ca and NMRI mice. RFB

induced multiple osteomas in $100 \%$ of the CBA/Ca mice. In NMRI mice, RFB induced osteopetrosis and malignant lymphoma in each $100 \%$ of the animals, and osteoma in $60 \%$ of the animals. The RFB provirus was molecularly cloned and completely sequenced for structural analysis. In comparison to murine leukemia viruses that are not known to influence the skeleton, amino acid sequence differences were found clustered in distinct regions of the genes for the group specific antigen, the polymerase and the envelope. The biological relevance of these sequence differences is presently under investigation.

The effect of the RFB on the expression of cellular genes was tested using a modification of the previously published method of differential display PCR (4). The primers used in the reactions were designed to detect modulated expression of RNA sequences with homology to helix-loop-helix (HLH) - type transcription factors. Expression of HLH-related sequence was investigated during osteogenic differentiation in mandibular condyles and in cultures of progenitor cells derived from mandibular condyles. The resuits showed that sequences related to HLH genes are temporarily expressed, and that the pattern of expression is different in RFB-infected cultures from that in uninfected cultures. A $3 \mathrm{~kb}$ transcript, which showed increasing expression levels during osteogenic differentiation of mandibular condyles has been partially cloned and sequenced.

Discussion

Chondrogenic cells from mandibular condyles and xiphoids from newborn mice can be "reprogrammed" during in vitro cultivation and are able to differentiate to the osteogenic or adipogenic lineage, respectively $(5,6,7)$. The cause underlaying this switch of the lineage program is not yet understood, however, it illustrates the versatility of the lineages of skeletal cell types. In mandibular condyles, the switch to the osteogenic lineage is further enforced by infection with RFB. After infection of the host cell, the proviral DNA becomes an integral part of the host genome. The activity of the proviral promoter (LTR, long terminal repeat) and/or proviral genes changes the normal physiology of the infected cells. This results in alterations of the normal skeletal growth, materializing in osteomas and osteopetrosis. The retrovirus-induced change of cell physiology is, at least in part, due to modulation of the expression of cellular genes. The resuits suggest that, in infected osteogenic cells, RFB modulates the expression of regulatory genes including transcription factors of the helix-loop-helix type. HLH genes are known to direct the differentiation of myogenic cells to myoblasts. It is intriguing to speculate that HLH-type transcription factors may also play a central role in osteogenic differentiation. Therefore, the in vitro and in vivo data indicate that the RFB retrovirus influences the basic lineage program of the infected skeletal cell.

Acknowledgement

This work was partly supported by the Deutsche Forschungsgemeinschaft (DFG grant STR 226).
References

1. Pedersen, L., P.G. Strauss, J. Schmidt, A. Luz, V. Erfle, P. Jørgensen, N.O. Kjeldgaard, and F.S. Pedersen. Pathogenicity of BALB/c derived N-tropic murine leukemia viruses. Virology $179,931-935,1990$

2. Pedersen, L., Behnisch, W., Schmidt, J., Luz, A., Pedersen, F.S., Erfle, V.,Strauss, P. G. Molecular cloning of osteoma-inducing replication-compctent murine leukemia viruses from the RFB osteoma virus stock. J.Virol. 66, 6186-6190, 1992

3. Schmidt, J., M. Casser-Bette, A. B. Murray, A. Luz, and V. Erfle. Retrovirus-induced osteopetrosis in mice. Effects of viral infection on osteogenic differcntiation in skeletoblast cell cultures. Am.J.Pathol, 129:503 - 510, 1987.

4. Liang, P. and A. B. Pardee. Differential display of cukaryotic, messenger RNA by means of the polymerase chain reaction. Science $257,967-971,1992$

5. Strauss, P.G., E.I. Closs, J. Schmidt, and V. Erfle. Gene expression during osteogenic differentiation in mandibular condylcs in vitro. J. Cell Biol. 110, 1369-1378, 1990.

6. Closs, E.I.,A.B. Murray, J. Schmidt, A. Schön, V. Erfle, and P.G. Strauss. C-fos expression precedes osteogenic differentiation of cartilage cells in vitro. J. Cell Biol. 111, 1313-1323, 1990.

7. Heermeier, K, Strauss, P. G., Erlle. V. and Schmidt, J. Adipose differentiation of cartilage in vitro. Differentiation $56,45-53,1994$ 
17P2-2

EXPRESSION OF FOS AND JUN FAMILY PROTEINS IN CULTURED CHICKEN CHONDROCYTES.

Hideo Iba, Takashi Kameda, Martha Harumi Sonobe, Masao Murakami and Hirotaka Watanabe.

Department of Tumor Virus Research, Institute of Medical Science, University of Tokyo, Tokyo, 108 JAPAN

The v-fos gene was first isolated in the genome of FBJ-MuSV, which causes osteosarcoma in mouse. Its cellular counterpart, c-fos and its related genes form a gene family. Their gene products and Jun proteins are the components of transcriptional factor AP- 1 and believed to be involved in cellular growth, differentiation and malignant transformation.

While c-fos as well as other fos family members is immediate early gene, which is transiently inducible by several extracellular stimuli in a variety of cell types, it is noteworthy that c-fos gene is reported to be constitutively expressed in fetal cartilage 1 or hypertropic chondrocytes 2 . To understand the biological function of AP-1 in chondrocytes, we have here analyzed the expression levels of all the components of AP- 1 in chicken chondrocytes. We also designed and constructed some transdominant mutants of Fos 3 or Jun 4 and further tested whether they can function as "a general inhibitor of AP-1", considering the future application to chondrocytes.

[Methods] Chondrocytes were isolated from the caudal or cephalic portion of sterna of 18 days old chicken embryo as described previously 5 with slight modifications. Cell cultures were pulse-labeled with 35S-methionine for 1 hour and cell lysates were prepared in denaturing conditions as described previously3. Immunoprecipitation was performed using anti- Fos pep I (crossreactive to all the Fos family proteins) ${ }^{6}$, anti-Fra-2 pep2 (Fra- 2 specific) ${ }^{6}$ and anti-Jun antiserum (cross reactive to all the Jun family proteins). Replication-competent avian retrovirus vectors 3,6 , infection protocols and colony formation assays were described previously 3,4 .

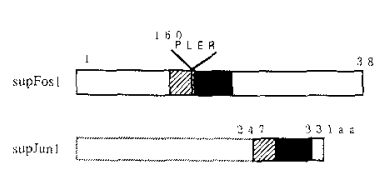

Table 1. Suppression of colony formation by supFos- 1 and supJun- 1 viruses.

\begin{tabular}{crc}
\hline & \multicolumn{2}{c}{ Suppression ratio } \\
Oncogene & supFos-1 & supJun-1 \\
\hline c-fos & 0.28 & 0.18 \\
fra-2 & 0.33 & 0.13 \\
c-jun & 0.25 & 0.05 \\
no oncogene & 1.0 & 1.0 \\
\hline
\end{tabular}

Fig. 1. Structure of the transdominant mutants.

1.0 indicates no suppression at all,while 0 indicates the complete suppression.

[Results and Discussion] Chicken chondrocytes that were prepared from either caudal or cephalic portion of sterna were kept in monolayer cultures. They were pulse-labeled with ${ }^{35} \mathrm{~S}$ methionine at various cultural stages $(4,11$ and 18 days after preparation) and disrupted in denaturing conditions to prepare cell lysates for immunoprecipitation. In all the cultures, we have detected a significant level of $c$-Fos expression, which apparent molecular weight was lower than that of highly phosphorylated forms of $c$-Fos $(62 K)$ that is transiently detectable in growthstimulated CFF. This result is quite different from CEF, where $\mathrm{C}$ Fos expression is detectable neither in logarithmically growing nor in resting cells 6 .

We also detected moderate levels of expression of Fra-2 which formed broad band of $40-47 \mathrm{~K}$. This migration pattern represents lower phosphorylation forms compared with Fra-2 (46$47 \mathrm{~K}$ ) detected in growth-induced CEF6. As for Jun proteins, high level expresson of $c$-Jun as well as low level expression of JunD were detected in all the cultures.

For the analysis of the biological function of constitutively expressed Fos or other components of AP- 1 in chondrocytes, development of a general inhibitor of AP- 1 would be useful. For this purpose, we have designed two putative transdominant mutants (Fig. 1). supFos- $1^{3}$ is derived from $v$-Fos and in vitro experiments have showed that it has full activity to form complex with c-Jun while the formed complex has completely lost DNA binding activity because of the insertion between the basic resion and the leucine zipper. c-Jun was deleted in its transforming region to generate another mutant, supJun-14. It can, however, form dimers with Fos or Jun proteins and the resultant dimers retain full DNA binding activity.

Using retrovirus vectors, either of these mutants were introduced into CEF, which were subsequently superinfected with c-jun, c-fos, or fra-2-carrying viruses. As judged from colony forming activity in soft agar (Table 1), expression of either supFos-1 or supJun-1 strongly suppressed the transformation by these oncogenes. This result indicate that both of the mutant functioned as transdominant inhibitors of AP-I-mediated transcriptional regulation. To introduce these mutants into chondrocytes, we are now in the process of screening the conditions for efficient infection to these cells.

[Acknowledgements] We thank Dr. Y. Kato and M. Iwamoto for introducing the preparation protocols for chicken chondrocytes. This work was partly supported by Grants-in-aid from Ministry of Education, Science and Culture of Japan.

[References]

1. Dony, C., \& Gruss, P. (1987) Nature 328,711-714.

2. Smeyne, R. J., Schilling K., Robertson, L., Luk D., Oberdick J., Curran, T., \& Morgan, J. I. (1992) Neuron 8, 13-23

3. Okuno, H., Suzuki, T., Yoshida, T., Hashimoto, Y., Curran, T., \& Iba, H. (1991) Oncogene 6, 1491-1497.

4. Suzuki, T., Murakami, M., Onai, N., Fukuda, E., Hushimoto, Y, Sonobe, M. H., Kameda, T., Ichinose, M., Kazumasa, M., \& Iba, H., (1994) J. Virol 68, 3527-3535.

5. Iwamoto, M., Golden, E. B., Adams, S. L., Noji, S., \& Pacifici, M. (1993) Exp. Cell Res. 205, 213-224.

6. Nishina, H., Sato, H., Suzuki, T., Sato, M., \& Iba, H. (1990) Proc. Natl. Acad. Sci. 87, 3619-3623

\section{$17 \mathrm{P} 2-3$}

HOMEOBOX-CONTAINING GENES AND GROWTH FACTORS IN
REGULATION OF LIMB OUTGROWTH, PATTERN FORMATION, REGULATION OF LIMB OUTGROWTH
AND CARTILAGE DIFFERENTIATION

Robert A. Kosher, Caroline N. Dealy, and William B. Upholt. Department of Anatomy, University of Connecticut Health Center, Farmington, Connecticut 06030, USA.

The outgrowth, patterning, and differentiation of the cartilaginous skeletal elements of the developing vertebrate limb involves a complex series of regulatory interactions among various homeobox-containing (hox) genes, growth factors, and other secreted signalling molecules. The apical ectodermal ridge (AER) at the distal tip of the limb bud maintains the mesenchymal cells directly subjacent to it in a rapidly proliferating, undifferentiated state. The roles and relationships among the hox genes $M S x$ $1, M s x-2$, and $D l x-5$, and the growth factors IGF-I, insulin, and FGFs in the AER/mesoderm interactions required for limb outgrowth and patterning will be discussed. When the subridge mesenchymal cells of the developing limb bud leave the influence of the AER, those located in the proximal central core of the limb bud initiate cartilage differentiation. The onset of chondrogenesis is characterized by a transient cellular condensation process during which intimate cell-cell and/or cell-matrix interactions occur that trigger chondrogenesis and the expression of genes for cartilage-specific matrix proteins including type II collagen, aggrecan, and type IX collagen. The toles of TGF-ps, BMPs, and the integral membrane heparan sulfate proteoglycan syndecan-3 in regulating the onset of condensation and cartilage differentiation will be discussed. Studies on the possible role of the hox gene Dlx-5, a member of the Distal-less family, in the regulation of cartilage-specific gene expression will be presented. 
18A-1

ROLE OF TIMPS AS GROWTH FACTORS IN THE PROLIFERATION OF ARTICULAR CHONDROCYTES

Kvoko Yamashita, Akira Shinagawa* and Taro Hayakawa. Department of Biochemistry, School of Dentistry, Aichi-Gakuin University, Nagoya 464, JAPAN and * Research Laboratories 1, Fuji Chemical Industries, Ltd., Toyama 933, JAPAN.

It has been well recognized that various tissue explants and cells synthesize and release matrix metalloproteinases (MMPs) and their intrinsic inhibitors called tissue inhibitors of metalloproteinases, TIMP-1 and TIMP-2. The ability of these TIMPs to inhibit MMPs suggest that they play an important role in the regulation of MMP activity, effectively controlling the amount of connective-tissue breakdown.

A number of reports have shown that cartilage contains collagenase inhibitors, and it has been suggested that these inhibitors could be responsible for the resistance of cartilage to vascularization and tumor invasion.

We recently reported that both TIMP-1 and -2 have potent cell growth-promoting activity for a wide range of cells $(1,2)$ and that this activity is independent of their MMP inhibitory activity. In this paper, we report the growth-promoting activity of both TIMPs toward bovine articular chondrocytes (BAC) and discuss their mechanism of action.

[Methods] Human recombinant TIMPs were expressed in the CHO. $\mathrm{K1}$ cell line and purified as described (2). BAC were isolated from slices of bovine ankle articular cartilage as reported earlier (3). TIMP-1 and TIMP-2 were determined by the corresponding one-step sandwich enzyme immunoassay $(4,5)$. TIMP-1- and TIMP-2-free FCS were prepared by the passage of FCS through anti-TIMP-1 (6) and antiTIMP-2 (5) monoclonal antibody-affinity columns, respectively. Stationary phase $\mathrm{BAC}$ were incubated at $37^{\circ} \mathrm{C}$ in D-MEM containing various amounts of either TIMP. Following incubation for various lengths of time, $0.8 \mu \mathrm{Ci} / \mathrm{ml}$ of $\left[{ }^{3} \mathrm{H}\right]$ thymidine $\left({ }^{3} \mathrm{H}\right.$-TdR) was added, and the cells were further incubated for $5 \mathrm{hrs}$ as described (2).

[Results] Both TIMP-1 and TIMP-2 contents in bovine articular cartilage were found to be $51.1 \pm 29.0$ and $56.5 \pm 16.8 \mathrm{ng} / \mathrm{g}$ wet tissue

(mean $\pm S D, n=6$ ), respectively. $B A C$ at the stationary phase and incubated for $48 \mathrm{hrs}$ at $37^{\circ} \mathrm{C}$ secreted both TIMP-1 $(37.0 \pm 6.6 \mathrm{ng} / \mathrm{ml}$, mean $\pm \mathrm{SD}, \mathrm{n}=3)$ and TIMP-2 $(36.3 \pm 4.0 \mathrm{ng} / \mathrm{ml})$ into their culture medium.

BAC were not able to grow in D-MEM alone. However, they grew significantly in D-MEM supplemented with either TIMP-1 or TIMP-2, with the maximal effect being at $500 \mathrm{ng} / \mathrm{ml}$ of TIMP-1 and $50 \mathrm{ng} / \mathrm{ml}$ of TIMP-2 (Table 1). We examined also the dose-dependent stimulation of DNA synthesis following the addition of either TIMP-1 or TIMP-2 to $\mathrm{BAC}$ at confluence, and obtained the maximal stimulation at either 50 $\mathrm{ng} / \mathrm{ml}$ of TIMP-1 or $1.0 \mathrm{ng} / \mathrm{ml}$ of TIMP-2. The cells showed a significant increase in ${ }^{3} \mathrm{H}-\mathrm{TdR}$ incorporation at as early as $\mathbf{3} \mathrm{hrs}$ after the addition of either TIMP, and the incorporation was maximal at $20 \mathrm{hrs}$. Either TIMP-1- or TIMP-2-dependent stimulation of DNA synthesis was dosedependently suppressed in the presence of tyrosine kinase inhibitors such as genistein and herbimycin $A$, but not in the presence of protein kinase inhibitors such as H-7 and K-252 b (Fig. 1). The proliferation of BAC was markedly suppressed in medium containing either TIMP-1- or TIMP-2-free FCS. The growth was, however, significantly restored by the addition of TIMPs.

[Discussion] ${ }^{3} \mathrm{H}-\mathrm{TdR}$ incorporation study suggested that both TIMPs seemed to directly stimulate the DNA synthesis of chondrocytes as new mitogens via the participation of receptor(s) possibly having tyrosine kinase activity. As it has been found that both TIMPs are constitutive components of human serum and FCS $(2,5)$, cell proliferation in nonvascular tissues such as articular cartilage seems to be more dependent on both TIMPs that are produced by the cartilage cells themselves.

[References]

1. Hayakawa, T., et al. (1992) FEBS Lett. 298, 29-32.

2. Hayakawa, T., et al. (1994) J. Cell Sci., in press.

3. Yasui, T., et al. (1992) Biomed. Res. 13, 343-348.

4. Kodama, S., et al. (1990) J. Immunol. Meth. 127, 103-108.

5. Fujimoto, N, et al. (1993) Clin. Chim. Acta 220,31-45.

6. Kodama, S. et al. (1987) Collagen Rel. Res. 7, 341-350.
Table 1. Effect of the addition of different concentrations of TIMP-1 and TIMP-2 on the proliferation of bovine articular chondrocytes in serum-free basal medium

\begin{tabular}{|c|c|c|c|}
\hline & $\begin{array}{c}\text { concentration } \\
\left(\mathrm{ng}^{\prime} / \mathrm{ml}\right)\end{array}$ & $\begin{array}{l}\text { DNA conlent } \\
\text { (ntidish) }\end{array}$ & E of controt \\
\hline day 0 & & 165 & 7.3 \\
\hline D-MEM alene & & $21 k \pm 8$ & $9.6 \pm 0.4$ \\
\hline$+10 \%$ FLS & & $2268 \pm 196$ & 100 \\
\hline * TIMP-L & $\begin{array}{r}5 \\
5 n \\
100 \\
500 \\
1000\end{array}$ & $\begin{array}{l}1265 \pm 68 \\
1343 \pm 54 \\
1400 \pm 100 \\
1600 \pm 99 \\
1234 \pm 97\end{array}$ & $\begin{array}{l}55.8 \pm 3.8 \\
59.2 \pm 2.4 \\
61.7 \pm 4.4 \\
70.6 \pm 4.4 \\
54.4 \pm 4.3\end{array}$ \\
\hline+ trmp-2 & $\begin{array}{r}1 \\
5 \\
10 \\
50 \\
100\end{array}$ & $\begin{array}{l}1261 \pm 62 \\
1241 \pm 83 \\
1373 \pm 51 \\
1509 \pm 75 \\
1295 \pm 58\end{array}$ & $\begin{array}{l}55.6 \pm 2.7 \\
54.7 \pm 3.7 \\
60.5 \pm 2.2 \\
66.5 \pm 3.3 \\
57.1 \pm 2.6\end{array}$ \\
\hline
\end{tabular}

Fig. 1. Effect of protein kinase inhibitors on TIMP-1- or TIMP-2-dependent stimulation of $\left[{ }^{3} \mathrm{H}\right]$ thymidine incorporation into bovine articular chondrocytes

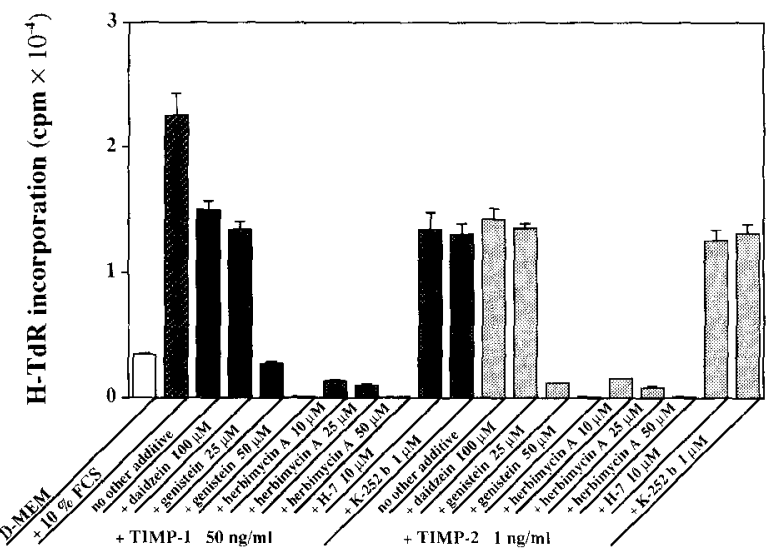




\section{A-2}

\section{THE ROLE OF HGF/SF IN CARTILAGE DEVELOPMENT}

Masahiro Iwamoto, Akitoshi Jikko ${ }^{1}$, Toshiaki Takebayashi ${ }^{2}$, Motomi EnomotoIwamoto ${ }^{3}$ Kunio Matsumoto ${ }^{4}$, Toshikazu Nakamura ${ }^{4}$, Kojiro Kurisu and Sumihare Noji ${ }^{5}$. Departments of Anatomy \& Cell Biology, ${ }^{1}$ Radiology and ${ }^{3}$ Biochemistry, Osaka University Faculty of Dentistry, Osaka, ${ }^{2}$ Okayama University Dental School, Okayama, ${ }^{4}$ Division of Biochemistry, Biomedical Research Center, Osaka University Medical School and ${ }^{5}$ Department of Bioengineering, Tokushima University Faculty of Engineering, Tokushima, JAPAN

Hepatocyte growth factor/ scatter factor (HGF/SF) is a multifunctional growth factor which promotes proliferation, motility, and morphogenesis of epithelial cells (1). Recently a HGF receptor, the c-met proto-oncogene product, has been reported to be expressed in developing limb buds (2), indicating that HGF/SF may play a role in limb development. In this study, we investigated the possibility that HGFISF is involved in the early skeletogenesis. We found that chondrocytes expressed a HGF/SF receptor and that HGF/SF stimulated the motility, proliferation and proteoglycan synthesis in chondrocytes. Further, in situ hybridization analysis showed that HGF/SF mRNA was restrictively expressed in the areas of the future joint regions in developing limb buds and in intercostal spaces near the tips of developing costal cartilages. These findings suggest that HGF/SF plays important roles in cartilage development by its multiple stimulatory actions on motility. proliferation and maturation of chondrocyles.

\section{[Materials and Methods]}

Cells and cell culture: Chondrocytes were isolated from 4-week-old New Zealand white rabbits or 4-week-old Wistar rats. Synovial fibroblasts were isolated from synovial tissue of the knee joints. Embryonic mesenchymal cells were isolated from the limb bud muscle tissue of 20-day rat embryos. Cells were maintained in DMEM supplemented with $10 \% \mathrm{FBS}, 60 \mu \mathrm{g} / \mathrm{ml}$ of kanamycin and fed every other day.

Measurement of DNA and proteoglycan synthesis; The rate of DNA synthesis was estimated by measuring the incorporation of [ ${ }^{3}-H T$-thymidine into $5 \%$ trichloroacetic acid-insoluble cell precipitate. Proteoglycan synthesis was determined by measuring incorporation of $\left[{ }^{35} \mathrm{~S}\right]$-sulfate into material precipitated with cetylpyridinium chloride after protease digestion

In situ hybridization; A $1.4 \mathrm{~kb}$ EcoRl fragment of a rat HGF/SF cDNA (RBC1 clone) was subcloned into the $\mathrm{PGEM} 7$ vector to synthesize both antisense and sense runoff transcripts labeled with [ $\alpha-{ }^{35}$ S]UTP (3). In situ hybridization was performed as described previously (3).

\section{[RESULT S]}

HGF/SF has motogenic and mitogenic activities on chondrocytes, but not on other mesenchymal cells.

We added HGF/SF exogenously in various cell cultures and observed changes in cell morphology. A typical culture of HGF/SF-treated articular chondrocytes is shown in Fig. 1. Without HGF/SF, polygonal chondrocytes proliferated and formed clusters (Fig. 1 Left), while no such clusters were observed in the presence of HGF/SF (Fig.1 Aight). In contrast to chondrocytes, HGF/SF scattered neither fibroblasts nor synovial cells.

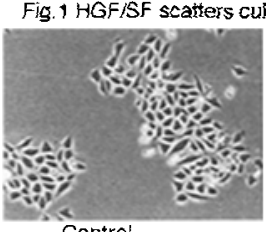

Control

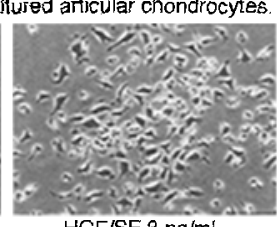

HGF/SF $3 \mathrm{ng} / \mathrm{m}$
To examine the effects of HGF/SF on proliferation of chondrocytes, the confluent cultures were serum-starved for $24 \mathrm{~h}$ and treated with various doses of KGF/SF. A dose-dependent increase in [ ${ }^{3} \mathrm{H}$-thymidine incorporation into DNA was observed in chondrocytes isolated from 4-week old rabbits and 23-day rabbit embryos. A maximum three-fold stimulation of DNA synthesis was observed in the presence of $1 \mathrm{ng} / \mathrm{ml} \mathrm{HGF/SF}$ while tibroblasts showed no response. Treatment with HGF (10 ng/ml) also increased cell number of articular chondrocytes about

1.8-told. Further, HGF/SF stimulated $\left[{ }^{35}\right.$ S $\}$-sulfate incorporation in chondrocytes in a dose dependent manner with a maximal stimulation at $1 \mathrm{ng} / \mathrm{ml}$ Expression of the HGF/SF receptor gene (c-met) in chondrochtes

The expression of $c$-met in chondrocytes in vivo and in vitro was examined by AT- PCR. Articular and rib cartilages were dissected out from 4-week old rats and total RNA was extracted. The extracted RNA was reverse transcribed, and amplified using c-met primers. We detected trace amounts of c-met expression in both articular and rib cartilages after 40 cycles of PCR amplifications. In contrast significant expression of c-met gene were detected in cultured chondrocytes after 35 cycles of PCR amplifications, indicating that cultured chondrocytes expressed higher levels of $\mathrm{c}$-met mRNA than cartilage in vivo. Expression of HGF/SF MRNA in the developing limb

We examined expression of HGF/SF mRNA by in situ hybridization analysis. In 1:-day embryos, diffuse expression of HGF/SF mRNA was detected around the proximal region of the limb. At this stage, no cartilaginous condensation occurred in the limb. As cartilaginous condensation proceeded, the expression of the HGF/SF gene became more restricted as shown in Fig. 2. At 12.5-14-days p.c., when stylopodial, zeugopodial and autopodial elements are formed, expression of the HGF/SF gene was observed at the future wrist/ankle and elbow/knee joint regions (Fig. 2). At later stage (16-days p. c.). HGF/SF transcripts were detected in the restricted mesenchymal cells adjacent to the cartilaginous condensations at the same wrist/ankle and elbow/knee regions. The level of HGF/SF gene expression in the limb decreased with development. Throughout the experiment, no significant signals for HGF/SF mRNA were detected in the hand or foot plates. No positive hybridization signal was detected in the precartilaginous condensations.

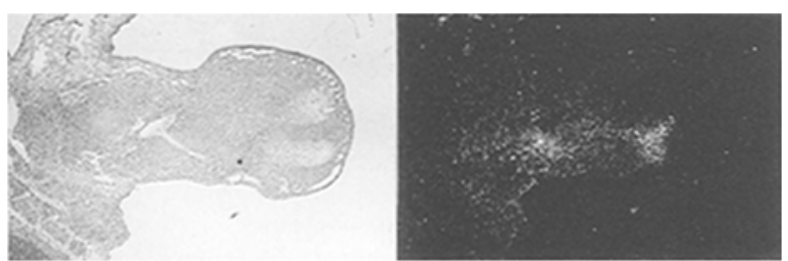

Fig. 2 Expression of HGF/SF in the developing limb. Sagittal sections of the hind limb of 14-days p.c. mouse embryos were hybridized with a ${ }^{35} \mathrm{~S}$-labeled rat HGF/SF riboprobe HGF/SF was expressed in the future knee and ankle joints.

\section{[Discussion]}

It is generally accepted that mesenchymal cells are sources of $\mathrm{HGF} / \mathrm{SF}$, but that they are not its target cells. The results of the present study, however, clearly demonstrated that chondrocytes express HGF/SF receptor and have the ability to respond to this factor. HGF/SF stimulates both proliferation and proteoglycan synthesis in chondrocytes. HGF/SF also functions as a motogen in these cells. No growth factors have been previously identified which modulate migration, proliferation, and proteogiycan synthesis by chondrocytes. In this study, HGF/SF was shown to be an unique multifunctional factor for chondrocytes and is likely to be involved in chondrogenesis or chondrocyte differentiation. Further, the expression pattern of the HGFISF gene in the developing limb and costal regions suggests physiological roles of HGF/SF in the control of skeletogenesis.

[Acknowledgements] This work was supported by Grants-in-Aid from the Ministry of Education. Science and Culture of Japan and by supports from Chugai Pharmaceutical Co. LTD., and Sumitomo Metal Industries, LTD.

\section{[References]}

1. Natsumoto, K And Nakamura, T. (1992) Oncogene 3, 27-54.

2. Sonnenberg. E. D. et al. (1993) J. Cell Biol. $123,223-235$

3. Noji S. et al. (1990) Biochem. Biophys. Res Comm. 173, 42-47. 
18A-3

INTERDEPENDENT REGULATION OF CHONDROCYTE DIFFERENTIATION BY TGF- $\beta$ AND VITAMIN $D_{3}$ METABOLITES

Zvi Schwartz, David Dean*, and Barbara Boyan*. Hebrew Univ., Jerusalem, Israe 91-010; *The Univ. of Texas Health Seience Center, San Antonio, Texas 78284 USA

\section{Introduction}

Transforming growth factor- $\beta$ (TGF- $\beta$ ) has been shown to modulate chondrocyte metabolism (1), but its precise role in chondrogenic differentiation is still uncertain due to the fact that different assay systems and cell types have been used. Some possibilitics that need to be considered in reconciling the prior studies include the fact that chondrocytes of varying stages of maturation were used $(2,3)$, that TGF- $\beta$ has direct effects on chondrocyte differentiation (4), and that TGF- $\beta$ is produced by those cells and released in latent form and then activated in the matrix (5).

The active metabolites of vitamin $\mathrm{D}, 1,25-(\mathrm{OH})_{2} \mathrm{D}_{3}(1,25)$ and $24,25-(\mathrm{OH})_{2} \mathrm{D}_{3}$ $(24,25)$, also play a critical role in chondrocyte metabolism (6). Boyan et al. (7) have shown that chondrocytes at clistinct stages of endochondral maturation resjond differentially to vitamin $\mathrm{D}_{3}$ metabolites. Vitamin $\mathrm{D}_{3}$ metabolites are also produced by the chondrocytes, themselves, in response to various hormones and growth factors (8).

The combination of TGl'- $\beta$ with other growth factors, hormones, or cytokines probably changes the net response of the target cell. Recently, we observed that 1,25 and TGF- $\beta$ synergistically enhanced alkaline phosphatase activity in osteoblasts in vilm (9). The present study was designed to evaluate the combined effect of vitamin $D_{3}$ metabolites and TGF- $\beta$ on chondrocyte differentiation. Moreover, this study examined the regulation of latent TGF- $\beta$ (LTGF- $\beta$ ) production by 1,25 and 24,25 , as well as the regulation of vitamin $1_{3}$ metabolite production by active TGF- $\beta$.

Methods

Chondrocytes were isolated from the resting zone (RC) and growth zono (GC) of rat costochondral cartilage (10). Cells were cultured in DMEM containing $10 \%$ fetal bovine serum (FBS), 1\% antibiotics, and $50 \mu \mathrm{g} / \mathrm{ml}$ ascorbic acid. Fourth passage cells were used in all experiments, since previous studies had shown retention of phenotype at this passage. Recombinant human TGF- $\beta 1(0.03-0.88 \mathrm{ng} / \mathrm{ml}), 1,25$ $\left(10^{10}-10^{-8} \mathrm{M}\right)$, and $24,25\left(10^{-9} \cdot 10^{-7} \mathrm{M}\right)$ wero added to confluent cultures for 24 hours. Alkaline phosphatase specific activity (ALPase) was measured in the cell layer. In some experiments, addition of both 'FGF- $\beta$ and vitamin $D_{3}$ metabolites to the cultures was examined at $3,6,12,24$, and 48 hours. For assay of $\left[{ }^{3} \mathrm{H}\right]$-thymidine incorporation, cells wore made quiescent, and the appropriate concentration of hormone or vehicle added, After 20 hours, $1 \mu \mathrm{Ci} / \mathrm{ml}$ of $\left[{ }^{3} \mathrm{H}\right]$-thymidine was added and rarliolabel incorporation into DNA measured four hours later negatively regulates terminal differentiation of GC cells to a calcifying phenotype, but enhances differentiation of less mature $\mathrm{RC}$ cells. Further, the regulation of chondrocytes by TGF- $\beta$ and vitamin $D_{3}$ metabolites is also dependent on their local production; that $i s$, vitamin D or TGF- $\beta$ have pronounced effects on TGF. $\beta, 1,25$, and 24,25 production by the chondrocytes. This suggests that regulation of chondrocytes in vivo is complex, involving interrelationships among hormones and growth factors. References

1. Centrella et al:: FASEB J 2:3066-3073, 1988.

2. Rosier et al.: Connect Tissue Res 20:295-301, 1989

3. Carrington et al.: Exp Cell Res 186:368.373, 1990.

4. Schwartz et al: Endocrinology 132:1514-1552, 1993.

5. Wakefield et al.: J Biol Chem 263:7646-7651, 1988.

6. Norman AW: Contrib Nephrol 18:1-11, 1980.

7. Boyan ot al.: Endocrinology 122:2851-2860, 1988.

8. Schwartzet al.: Endocrinology 130:2495-2504, 1992.

9. Bonewald et al.: J Biol Chem 267:8943-8949, 1992.

10. Boyan et al.: Bone $9: 185-194,1988$.

The release of latent and active TGF- $\beta$ by chondrocytes treated with 1,25 or 24,25 was examined. Conditioned merlia were assayed for active and latent TGF- $\beta$ content by measuring growth factor-dependent increases in ALPase of ROS 17/2 8 osteoblast-like cells before and after acid activation. The specificity of this assay was confirmed with pan-neutralizing antibodies to TGF- $\beta$. The synthesis of 1,25 and 24,25 from $\left[{ }^{3} \mathrm{H}\right] \cdot 25 \cdot(\mathrm{OH})_{2} \mathrm{D}_{3}$ by cultures treated with TGF- $\beta$ was measured by a previously described HPL_C technique using radioisotope detection (8) Results

Addition of 1,25 to GC cells resulted in a dose-dependent increase in ALPase while TGF. $\beta$ stimulated AI.Pase in a biphasic manner at $0.06-0.22 \mathrm{ng} / \mathrm{ml}$ of TGF- $\beta$. Addition of both 1,25 and TGF- $\beta$ increased $\Lambda$ LPase to a level similar to that observed with TGE $\beta$ alone. These effects were also observed after treatment for 3 to $48 \mathrm{~h}$. The addition of 24,25 to $\mathrm{GC}$ cells harl no effect on ALPase; the effect of I'GF- $\beta$ in combination with 24,25 was identical to that observed with TGF- $\beta$ alone.

1,25 dose-dependently inhilited $\left[{ }^{3} \mathrm{H}\right]-$ thymidine incorporation by GC cells, while TGF- $\beta$ produced a dose-dejendent increase in ${ }^{3}[\mathrm{H}]$-thymidine incorporation. The addition of both 1,25 and TGF- $\beta$ significantly inhibited $\left[{ }^{3} \mathrm{H}\right]$-thymidine incorporation at low TGF- $\beta$ concentrations $(0.03 \cdot 0.11 \mathrm{ng} / \mathrm{ml})$.

No change in ALPase was detected in RC cell layers after incubation with either 1,25 or 24,25 ; however, biphasic stimulation of $\triangle L P a s e$ was observed after addition of $0.06-0.22 \mathrm{ng} / \mathrm{ml}$ TGF- $\beta$. The combination of 24,25 and TGF. $\beta$ significantly increased ALPase to more than twice that found with TGF- $\beta$ alone. These effects were also observed after treatment for 3 to $48 \mathrm{~h}$.

The effect of TGF- $\beta$ and 24,25 on $\mathrm{F}^{3} 11$-thymidine incorporation by RC cells was similar to that observed with GC cells treated with 1,25 and TGF- $\beta$. Lower coneentrations of TGF- $\beta$ inhibited $\left[{ }^{3} \mathrm{H}\right]$-thymidine incorporation, while higher ones had no effect; or stimulated DNA synthesis.

The addition of 1,25 to either GC or RC cultures inhibited release of LTGF- $\beta$ into the medium; no active TGF- $\beta$ was detected. In contrast, the addition of 24,25 to GC or RC cultures had no effect on LTGF- $\beta$ produetion. Treatment of RC cells with active TGF- $\beta$ for $24 \mathrm{~h}$ dose-dependently increased synthesis of 24,25 , while it inhibited synthesis of 1,25 by RC cells. Synthesis of vitamin D metabolites by GC cells was unaffected by incubation with TGF- $B$.

Discussion

Vitamin D metabolite inhibition of TGF- $\beta$-induced stimulation of $\mathrm{L}^{3} \mathrm{~F}[\mathrm{]}$-thymidine incorporation suggests that growth factor and hormone promote differentiation of both GC and RC cells, but only when coupled with the metabolite appropriate to the target cell. In GC cells, TGF- $\beta$ appears to modulate 1,25 -dependent effects by maintaining or even decreasing ALPase. This differs from the synergiatic increases in ALPase seen in osteoblast-like ROS $17 / 2.8$ cells (9), but is similar to the effect of TGF. $\beta$ and 24,25 on RC cells. This data supports the hypothesis that TGF. $\beta$ 
$18 \mathrm{~A}-4$

NONGENOMIC MECHANISMS OF VITAMIN D ACTION IN GROWTH PLATE CHONDROGENESIS

Barbara D Bovan, David D. Dean, Victor Sylvia and Zvi Schwartz*. University of
Texas Health Science Center at San Antonio, Texas 78284 USA; *Hebrew University Hadassah Faculty of Dental Medicine, Jerusalem, Israel

\section{Introduction}

Chondrocyte proliferation, motabolism, and differentiation are regulated by vitamin $\mathrm{D}$ in vivo and in vito. Cellular response is dependent on the state of chondrogenic maturation. While cells derived from the resting zone (reserve zone) respond primarily to $24,25-(\mathrm{OH})_{2} \mathrm{D}_{3}$, cells from the growth zone (prehypertrophic and upper hypertrophic zones) respond primarily to $1,25-(\mathrm{OH})_{2} \mathrm{D}_{3}$. This phenotypic difference in vitamin $D$ matabolite preference is obscrved in vivo as well. Rachitic rat tibias can be healed by direct injection of $24,25-(\mathrm{OH})_{2} \mathrm{D}_{3}$ into the resting zone or $1,25-(\mathrm{OH})_{2} \mathrm{D}_{3}$ in to the hypertrophic zone $(1,2)$.

Many of the effects of vitamin D metabolites involve genomic events. Receptors for both 1,25- $(\mathrm{OH})_{2} \mathrm{D}_{3}$ and $24,25-(\mathrm{OH})_{2} \mathrm{D}_{3}$ have been found in cartilage $(3$. 5) and several studies have shown that new gene expression and irolein synthesis occur. It is becoming increasingly clear, however, that vitamin D motabolites can accur. It, is beconing increasingly clear, however, that vitamin D motatolics can also excrt their effects through nongenomic mechanisms; that is, changes in gene
transcription, mRNA stabilization, or protein synthesis do not occur. Fxamples of transcription, mRNA stabilization, or protein synthesis do not occur. Fxamples of
nongenomic actions of vitamin D metabolites in cultures of resting zone and growth zone chondrocytes include changes in calcium flux, arachidonic acid turnover. membrane fluidity, and protein kinase $C$ activity [PKC] (6-9).

Nongenomic mechanisms are parlicularly important in growth plate chondrogenesis where cells not only need to synthesize extracellular matrix, but: must also modify it to accommorlate cell hypertrophy and facilitate calcification. Cartilage cells une it to a

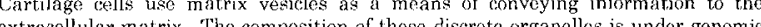
extracellular matrix. The composition of these discrete organelles is under genomic
control. Thus, matrix vesicles produced by resting zone cells differ from those control. Thus, matrix vesicles produced by resting zone cells differ from those
produced by growth zone cells. Matrix vesicles are unicue membrane bound entities since they have a distinct phospholipid composition and independont phospholipid motabolism, and are enriched in alkaline phosphatase specific activity when compared with the plasma memlurane of the cell from which they were derived. In addition, they contain enzymes associated with calcification [such as alkaline johosphatase, phospholipase $A_{2}$. NTP pyrophosphohydrolase] and matrix processing [iuch as acid ani neutral metalloproteinases, gelatinase, and plasminoyen activator (10-11).

The sturlics described in this paper oxamined whether chondrocytes can regulate matrix vesiclos via nongenomic inturactions with vitamin $D$ metabolites. To do this, we adklressed the following questions. Can chondrocytes produce vitamin 1) metabolites? Is metabolite production regulated? Can matrix vesicle enzyme activity be directly regulated by vitamin D metaboliles? Are the direct effects of $1,25-(\mathrm{OH})_{2} \mathrm{D}_{3}$ and $24,25 \cdot(\mathrm{OH})_{2} \mathrm{D}_{3}$ cell maturation-(lependent? Do the vitamin $\mathrm{D}$ metabolitics alter matrix vesicle membrane fluidity? Are the vitamin D effects mediated through ' $\mathrm{KC}$ ? Can the direct action of $1,25 \cdot(\mathrm{OH} 1)_{2} \mathrm{D}_{3}$ or $21,25 \cdot(\mathrm{OH})_{2} \mathrm{D}_{3}$ on matrix vecicles result in foedback of information to the cell?

Methods

Resting zone ( $\mathrm{RC}$ ) and growth zone (GC) chondrocytes wore isolated from rat castochondral cartilage and cultured in DMFM containing $10 \% \mathrm{FBS}, 50 \mu \mathrm{g} / \mathrm{ml}$ ascorbic acid, and $1 \%$ antibiotice in an atmosphere of $5 \% \mathrm{CO}_{2}$ and $100 \%$ humidity at $37^{\circ} \mathrm{C}$. Effects of exogenous $1,25-(\mathrm{OH})_{2} \mathrm{D}_{3}, 24,25-(\mathrm{OH})_{2} \mathrm{D}_{3}, \mathrm{TGF} \beta$, and dexamethasone on vitamin $\mathrm{D}$ metabolite production were assessed by using $\left[{ }^{3} \mathrm{H}\right]-25 \cdot(\mathrm{OH}) \mathrm{D}_{3}$ as a substrate: the resultant vitamin D metabolites synthesized and released into the medium were separated by HPLC and detectod by a radioisotope method (12).

Alkaline phosphatase and phospholipase $A_{2}$ specific activities in matrix vesicles were assayed as described before (10). Activity in matrix vesicles isolated vesicles were assayed as described before (10). Activity in matrix vesicles isolated from cultures that had been treated with hormone were compared to those
incubated directly with $1,25-(\mathrm{OH})_{2} \mathrm{D}_{3}$ or $24,25-(\mathrm{OH})_{2} \mathrm{D}_{3}$. "The effect of $1,25-(\mathrm{OH})_{2} \mathrm{D}_{3}$ and $24,25-(\mathrm{OII})_{2} \mathrm{D}_{3}$ on matrix vesicle membrane fluidity was assessed by measuring the anisotropy of membranes pre-labeled with the fluoroprobe, 'TM $\Lambda$-DPH (8). The PKC specific activity of isolated matrix vesicles and plasma membranes was assayed by measuring the phosphorylation of myelin basic protein with ${ }^{32} \mathrm{P}$ (9). The identity of specific PKC isoforms was determined by use of specific antibodies. The ability of 1,25-(OH), $\mathrm{D}_{3}$ or $24,25-(\mathrm{OH})_{2} \mathrm{D}_{3}$ to stimulate the activation of latent TGF 3 by isolated GC and RC matrix vesicles, respectively, was also examined.

Results

When $\mathrm{GC}$ cells were exposed to $1,25-(\mathrm{OH})_{2} \mathrm{D}_{3}$, there was a rlose-dependent increase in matrix vesicle alkaline phosphatase and phospholipase $A_{2}$, whereas $24,25-(\mathrm{OH})_{2} \mathrm{D}_{3}$ had no effect. Similarly, $1,25-(\mathrm{OH})_{2} \mathrm{D}_{3}$ stimulated alkatine phosphatase and phospholipase $\Lambda_{2}$ when incubatesl directly with isolated GC matrix vesicles, and $24,25-(O T)_{2} D_{3}$ had no effect. When RC cells were exposed to $24,25 \cdot(\mathrm{OH})_{2} \mathrm{D}_{3}$, there was a dose-dependent increase in matrix vesicle alkaline phosphalase, but a decruase on phospholipase $\Lambda_{2}$. When isolated RC matrix vosicles were incubated directly with $24,25-(\mathrm{OH})_{2} \mathrm{I}_{3}$, similar effects on enzyme activity were were incubated ditectly with $24,25-(\mathrm{OH})_{2} \mathrm{C}_{3}$, simit.

$1,25-(\mathrm{OH})_{2} \mathrm{D}_{3}$ increased $\mathrm{GC}$ matrix vesicle membrane fluidity, while $21,25-(\mathrm{OH})_{2} \mathrm{D}_{3}$ hadl a similar effect on $\mathrm{RC}$ matrix vesicle membranc fluidity. 'The obscrvel effects were motabolite. kpecific to each cell typo.

Matrix vesicles contained PKC activity that was distinct from that of the plasma membrane. By use of isoform-specific antibolies, matrix vesicles were shown to contain predominantly PKC , while plasma membranes contained $\mathrm{PKC} \alpha$. When GC and RC matrix vesicles were incubated directly with $1,25-(\mathrm{OH})_{3} \mathrm{D}_{3}$ and $\left.24.25-(\mathrm{OH})_{0} \mathrm{l}\right)$, respectively, $\mathrm{PKCC}$ was inhibited. In contrasi, plasma membrane PKC $\alpha$ was stimulated by the vitamin $D$ metabolites.

Both $R \mathrm{C}$ and $\mathrm{CO}$ chondrocytes proluce $1,25-(\mathrm{O}) 1)_{2} \mathrm{D}_{3}$ and $24,25 \cdot(\mathrm{OI})_{2} \mathrm{D}_{3}$ constitutively, although the amounts vary with celli type. In general, production of $1,25-(\mathrm{OH})_{2} \mathrm{D}_{3}$ is down-regulated by $1.25-(\mathrm{OH}), \mathrm{D}_{3}$ and up-regulated by $24,25 \cdot(\mathrm{OH})_{2} \mathrm{D}_{3}$. Conversely, production of $24,25-\left(6 \mathrm{H}_{3}\right)_{3} \mathrm{D}_{3}$ is chown-regulated by $24,25 \cdot(\mathrm{OH})_{2} \mathrm{l}_{3}$ and up-regulated by $1,25-(\mathrm{OH})_{2} \mathrm{D}_{3}$. Metabolite production is also regulated by TGF- $\beta$ and dexamethasone in a cell maturation- and time-dependent manner.

1,25-(OF $)_{2} \mathrm{~b}$, stimulated activation of latent $\mathrm{TCF} \beta$ by GC matrix vesicles, but hal no effect on RC matrix vesicles. Further, $24,25-(\mathrm{OH})_{2} \mathrm{D}_{3}$ had no effect on activation of latent. TCF 3 by matrix vesieles isolated from either cell type.
Discussion and Conclusion

These results show that both $1,25-(\mathrm{OH})_{2} \mathrm{D}_{3}$ and $24,25-(\mathrm{OH})_{2} \mathrm{D}_{3}$ can directly affect matrix vesicles via nongenomic pathways. T'wo mechanisms which appear to play a role are changes in membrane fluidity and inhibition of $\mathrm{PKC}$. The specific effects of each hormone are conferred by cell maturation-specific differences in matrix vesicle composition. In addition, the nongenomic effects on matrix vesicles can be differentiated from effects on plasma membranes by both phospholipid composition and general enzyme distribution, as well as by isoforms of PKC. The ability of matrix vesicles to activate latent TGF $B$ is both cell maturation-dependent ability of matric vesicles to activate latent $T F B$ is both cell maturation-dependent and metalolite-specitic, inticating that nongenomic effects of vitamin $D$ can have
direct physiologic consequences. Activated TCF $\beta$ may act back on the chondrocytes to regulate differentiation, as well as vitamin D metabolite production.

\section{Acknowledgments}

These studies wore supported by PHS grants DF,08603 and DE05937.

References

1. Atkin I, Pita JC, Ornoy A, Agundez A, Castiglione G, and Howell DS. Bone 6:1.13-123, 1985

2. Lidor C, Atkin I Ornoy A Dekel S and Edelstein S. J Bone Min Res 291-98, 1987.

3. Corvol M, UJmann A, and Garabedian M. FEBS Lett. 1 16:273-278, 1980

4. Balmain $\mathrm{N}$, Hauchecome $M$, Pike JW, Cuisimer-Gleizes $P$, and Matlieu $\mathrm{H}$. Cell Molec Biol 39:339-350, 1993.

5. Fine N, Binderman I, Somjen D, Faron $Y$, Edelstein $S$, and Weisman Y. Bone 6:99-106, 1985

6. Schwartz Z, Langston GG, Swain LD, and Boyan BD. J Bone Min Res 6:709$718,1991$.

7. Swain J1), Schwart: Z, and Boyan BD. Biochim Biophys Acta 1136.45-51, 1992

8. Swain I.D, Schwart\% 7, Caulfield $\mathrm{K}$, Brooks RP, ant Boyan BD. Bone 14:009. 617,1993 .

9. Sy]via VI, Schwart: \%. Shuman L, Morgan RT', Mackey S, Gomoz R, and Boyan BD. J Coll I'hysiol 175:271.278, 1993

10. Schwartz Z, Schlader DL, Swain LD, and Boyan BL). Endocrinology 123:2878. $2884,1988$.

11. Dean DD, Schwartz Z, Muniz OE, Gomez R, Swain LD, Howoll DS, and Boyan BD. Calcif'tissue Int 50:342-349, 1992

12. Schwartz 7, Brooks BP. Swain J.D, Del Toro F, Norman A, and Boyan BD. Endocrinology 130:2495.2504, 1992. 